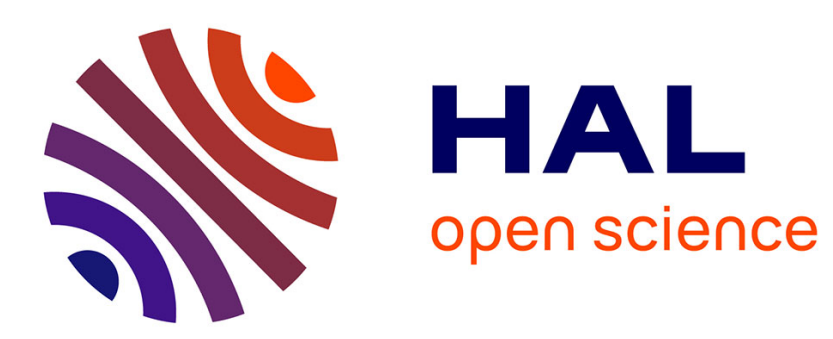

\title{
Many-body calculations of molecular electric polarizabilities in asymptotically complete basis sets
}

Ruben Monten, Balazs Hajgato, Michael S. Deleuze

\section{To cite this version:}

Ruben Monten, Balazs Hajgato, Michael S. Deleuze. Many-body calculations of molecular electric polarizabilities in asymptotically complete basis sets. Molecular Physics, 2011, 109 (19), pp.23172339. 10.1080/00268976.2011.579580 . hal-00743833

\section{HAL Id: hal-00743833 \\ https://hal.science/hal-00743833}

Submitted on 21 Oct 2012

HAL is a multi-disciplinary open access archive for the deposit and dissemination of scientific research documents, whether they are published or not. The documents may come from teaching and research institutions in France or abroad, or from public or private research centers.
L'archive ouverte pluridisciplinaire HAL, est destinée au dépôt et à la diffusion de documents scientifiques de niveau recherche, publiés ou non, émanant des établissements d'enseignement et de recherche français ou étrangers, des laboratoires publics ou privés. 


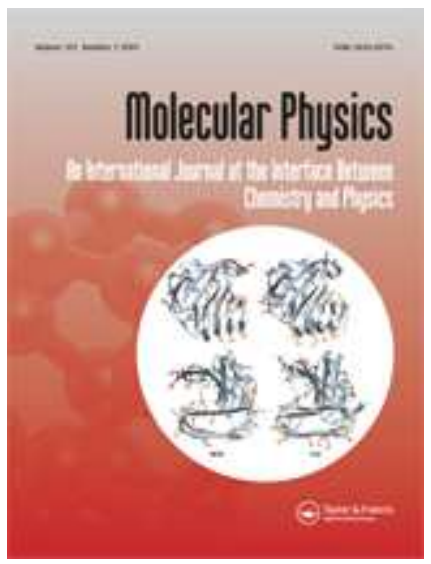

\section{Many-body calculations of molecular electric polarizabilities in asymptotically complete basis sets}

\begin{tabular}{|r|l|}
\hline Journal: & Molecular Physics \\
\hline Manuscript ID: & TMPH-2010-0472.R2 \\
\hline Manuscript Type: & Full Paper \\
\hline Date Submitted by the & 28-Mar-2011 \\
\hline Complete List of Authors: & $\begin{array}{l}\text { Monten, Ruben; Hasselt University, Theoretical Chemistry and } \\
\text { Molecular Modelling } \\
\text { Hajgato, Balazs; Hasselt University, Theoretical Chemistry and } \\
\text { Molecular Modelling } \\
\text { Deleuze, Michael; Hasselt University, Theoretical Chemistry }\end{array}$ \\
\hline Keywords: & $\begin{array}{l}\text { electronic polarizability, electronic correlation, energy extrapolation, } \\
\text { asymptotically complete basis sets, chemical accuracy }\end{array}$ \\
\hline \hline & \\
\hline $\begin{array}{l}\text { Note: The following files were submitted by the author for peer review, but cannot be converted } \\
\text { to PDF. You must view these files (e.g. movies) online. }\end{array}$ & \\
\hline Polar_figures.zip &
\end{tabular}

\section{SCHOLARONE \\ Manuscripts}




\title{
Many-body calculations of molecular electric polarizabilities in asymptotically complete basis sets
}

\author{
Ruben Monten, Balázs Hajgató, Michael S. Deleuze* \\ Theoretical Chemistry and Molecular Modelling, Hasselt University, Agoralaan, Gebouw D, B- \\ 3590 Diepenbeek, Belgium.
}

\footnotetext{
*Corresponding author. E-mail: michael.deleuze@uhasselt.be
} 


\title{
Many-body calculations of molecular electric polarizabilities in asymptotically complete basis sets
}

\author{
Ruben Monten, Balázs Hajgató, Michael S. Deleuze* \\ Theoretical Chemistry and Molecular Modelling, Hasselt University, Agoralaan, Gebouw D, B- \\ 3590 Diepenbeek, Belgium.
}

\begin{abstract}
The static dipole polarizabilities of $\mathrm{Ne}, \mathrm{CO}, \mathrm{N}_{2}, \mathrm{~F}_{2}, \mathrm{HF}, \mathrm{H}_{2} \mathrm{O}, \mathrm{HCN}$, and $\mathrm{C}_{2} \mathrm{H}_{2}$ (acetylene) have been determined close to the Full-CI limit along with an asymptotically complete basis set (CBS), according to the principles of a Focal Point Analysis. In this purpose we employed the results of Finite Field calculations up to the level of Coupled Cluster theory including Single, Double, Triple, Quadruple and perturbative Pentuple excitations [CCSDTQ(P)], in conjunction with suited extrapolations of energies obtained using augmented and doubly-augmented Dunning's correlation consistent polarized valence basis sets of improving quality. The polarizability characteristics of $\mathrm{C}_{2} \mathrm{H}_{4}$ (ethylene) and $\mathrm{C}_{2} \mathrm{H}_{6}$ (ethane) have been determined on the same grounds at the CCSDTQ level in the CBS limit. Comparison is made with results obtained using lower levels in electronic correlation, or taking into account the relaxation of the molecular structure due to an adiabatic polarization process. Vibrational corrections to electronic polarizabilities have been empirically estimated according to Born-Oppenheimer Molecular Dynamical simulations employing Density Functional Theory. Confrontation with experiment ultimately indicates relative accuracies of the order of 1 to $2 \%$.
\end{abstract}

Keywords: electronic polarizability, molecular relaxation, electronic correlation, energy extrapolation, asymptotically complete basis sets, chemical accuracy.

\section{Introduction}

Computation of linear molecular responses to an external field is a topic of considerable and long standing interest in physics and chemistry [1]. Static dipole polarizabilities are most important properties which participate in many physical phenomena, e.g. Stark effect, dielectric polarization and intermolecular dispersion forces. These measure at first order the change in the molecular dipole moment when an external homogenous and frequency-independent electric field is applied:

$$
\mu_{i}(\vec{F})=\mu_{i}(\overrightarrow{0})+\sum_{j} \alpha_{i j} F_{j}+\cdots
$$

The polarizability tensor $\left[\alpha_{i j}\{i=x, y, z ; j=x, y, z\}\right]$ is an electric property that can be cast in terms of second-order energy derivatives [2] with respect to the external static electric field, since:

$$
E(\vec{F})=E(\overrightarrow{0})-\sum_{i} \mu_{i} F_{i}-\frac{1}{2} \sum_{i j} \alpha_{i j} F_{i} F_{j}-\cdots
$$

A main rotational invariant is the isotropic polarizability, defined as:

\footnotetext{
${ }^{*}$ Corresponding author. E-mail: michael.deleuze@uhasselt.be
} 


$$
\bar{\alpha}=\frac{1}{3}\left(\alpha_{x x}+\alpha_{y y}+\alpha_{z z}\right)
$$

Three decades ago, agreement between experimentally derived and theoretically predicted polarizabilities was a major issue [3]. Since then, various aspects of the theoretical determination of polarizabilities have been examined in depth in comprehensive reviews [4]. On the experimental side, one has witnessed the development of numerous methods for measuring polarizabilities, such as refraction, scattering and birefringence measurements [5], Kerr-effect experiments [6], electric field induced harmonic generations [7], Laser Stark-effect spectroscopy [8], or deflection experiments in inhomogenous electric fields (see e.g. [9]).

It is now well-established that energies and related response properties are rather sensitive to electron correlation and to the employed basis set, in particular to the incorporation of polarization and diffuse functions [10]. Unfortunately, large scale treatments of electron correlation remain most often far too prohibitive for straightforward applications upon compounds of great practical relevance, as for instance large conjugated systems in non-linear optics [11]. In such situations, one of the most affordable options for reaching the so-called chemical accuracy on energies $[1 \mathrm{kcal} / \mathrm{mol}$; i.e. $0.043 \mathrm{eV}$ ] consists in exploiting separately the faster convergence with respect to the basis set of the highest-order correlation corrections to energies, by virtue of the principles of a Focal Point Analysis [12]. The interested reader is referred in particular to highly quantitative theoretical determinations, within chemical accuracy ( $1 \mathrm{kcal} / \mathrm{mol}$, i.e. $0.043 \mathrm{eV})$ of the ionization, electron attachment and singlet-triplet excitation energies of large oligoacenes [13], which are notoriously difficult, i.e. strongly correlated, compounds.

The scope of the present study is to pursue the static polarizabilities of small but highly representative molecules at the confines of non-relativistic quantum mechanics, i.e. close to the limit of an exact (Full-CI) solution of the many-electron Schrödinger equation [14], within the framework of the Born-Oppenheimer approximation. More specifically, and in line with our recent work on acenes [13], we aim first at determining how these properties converge to the CCSD(T)/CBS level [i.e. Coupled Cluster Theory along with Single, Double and perturbative Triple 
electronic excitations [15], in conjunction with an asymptotically complete basis set (CBS)] when using well-established hierarchies of basis sets and size-consistent many-electron wave function theories, along with the finite field approach [16]. The principles of a Focal Point Analysis (FPA $[12,13])$ are thereafter applied in order to evaluate the static dipole electric dipole polarizabilities at much higher levels in correlation, practically at the Full-CI/CBS limit, by combining pairwise results obtained using Coupled Cluster treatments of electron correlation and basis sets of improving quality. In the present work, we focus on the influence of electronic correlation onto static dipole polarizabilities of clamped nuclei configurations that correspond to energy minima in the absence of an external field, and disregard in a first stage direct and indirect vibrational contributions associated to vibrational excitations and changes in the electronic polarizability due to ro-vibrational distortions of the molecular structure, in the absence of an external field. Vibrationally averaged results for isotropic polarizabilities at $298 \mathrm{~K}$ are thereafter obtained by combining our best FPA estimates with corrections derived from classical trajectory simulations, using Born-Oppenheimer Molecular Dynamics [17].

Most experimental determinations of static polarizabilities derive from extrapolation to the zerofrequency limit of experiments (e.g. refraction measurements) employing electric or electromagnetic fields with high frequencies (usually in the UV-Vis regime), and may be ascribed therefore to the immediate response of the electron cloud to the external electric field, regardless of the slower induced nuclear motions. In this limit, it is thus most customary to neglect induced geometrical relaxation effects and to compute polarizabilities from second-order derivatives of the electronic energy. In sharp contrast, molecular structural relaxation effects are known to play a significant role in deflection experiments upon polarizable systems submitted to electric field gradients [9c], due to the inherently much longer time scale for the interaction between the molecule and the external field. These effects should also be inherent to determinations of polarizabilities of free molecules by means of Laser Stark Spectroscopy, which is based on measurements of electric field induced splittings and shifts of single rotational lines. In our work, 
we therefore wish also to evaluate up to the $\operatorname{CCSD}(\mathrm{T}) / \mathrm{CBS}$ level the influence of geometrical relaxation upon static dipole polarizabilities, assuming an adiabatic (i.e. on a long time scale) response of the nuclear configuration to the external field.

\section{Methodology}

Relating linear molecular properties to second-order derivatives of the energy allows all standard post-SCF quantum chemical techniques for calculating energies at a correlated level to be used, and thus bypasses the need for more elaborate, specific analytical many-body approaches, as for instance Polarization Propagator [18] or Coupled Perturbed Electron Propagator [19] theories. However, in order to minimize non-linear effects, which are most commonly enhanced when electron correlation is included, one has to limit the extent of the external perturbation, and the energy differences to compute are therefore rather small. On the other hand, the field has still to be large enough in order to induce energy differences that are substantially more important than the uncertainties due to the employed approximations and numerical errors. For instance, exceedingly accurate results upon numerical energy differences, within $10^{-9}$ a.u. uncertainty $\left(1\right.$ a.u. $=1 \mathrm{E}_{\mathrm{h}}=$ $4.359748210^{-18} \mathrm{~J}$ ), are required for computing polarizabilities within an accuracy of $10^{-2}$ a.u. (1 a.u. $\left.=1 \mathrm{e}^{2} \mathrm{a}_{0}^{2} \mathrm{E}_{\mathrm{h}}^{-1}=1.64877810^{-41} \mathrm{C}^{2} \mathrm{~m}^{2} \mathrm{~J}^{-1}\right)$, using 0.0003 a.u. $\left(1\right.$ a.u. $\left.=\mathrm{E}_{\mathrm{h}} \mathrm{e}^{-1} \mathrm{a}_{0}{ }^{-1}=5.14210^{11} \mathrm{~V} \mathrm{~m}^{-1}\right)$ as the basic step size on the field.

All calculations that are presented in the sequel for $\mathrm{CO}, \mathrm{N}_{2}, \mathrm{~F}_{2}, \mathrm{HF}$ and $\mathrm{H}_{2} \mathrm{O}$ are based on molecular geometries that were optimized using $\operatorname{CCSD}(\mathrm{T})$ [15], along with the aug-cc-pV5Z and daug-cc-pV5Z basis sets [20] (Dunning's correlation consistent polarized valence basis set of pentuple zeta quality, augmented by a double set of diffuse functions). Geometry optimizations for the $\mathrm{HCN}, \mathrm{HCCH}$, and $\mathrm{C}_{2} \mathrm{H}_{4}$ molecules are carried out at the $\mathrm{CCSD}(\mathrm{T}) /$ aug-cc-pV5Z level. The geometry of $\mathrm{C}_{2} \mathrm{H}_{6}$ was treated at the $\mathrm{CCSD}(\mathrm{T}) /$ aug-cc-pVQZ level. The convergence thresholds on HF and CCSD energies were set to $10^{-11}$ a.u. and $10^{-10}$ a.u., respectively ( 1 a.u. $=1$ hartree). In addition, the maximum step size over atomic displacements (in internal coordinates) and energy 
gradients (forces) at final convergence were set equal to $1 \times 10^{-6}$ a.u. (bohr or radian) and $2 \times 10^{-6}$ a.u. (hartree/bohr), respectively.

Electric polarizabilities were subsequently calculated at various theoretical levels [Hartree-Fock (HF), $2^{\text {nd }}, 3^{\text {rd }}$ and (truncated) $4^{\text {th }}$ order Møller-Plesset Perturbation (MP2 [21,22], MP3, MP4SDQ [23]), CCSD [24], and $\operatorname{CCSD}(\mathrm{T})$ [15] theories, in conjunction with basis sets of improving quality. Calculations were performed upon standard molecular orientations defined from the main symmetry elements of the target, according to the conventions described in the book by Jaffé and Orchin [25], so that all off-diagonal components of the polarizability tensor identically vanish. The diagonal components were determined according to equation (2) from second-order derivatives of the energy with respect to the relevant components of the field, using a second-order polynomial least squares fit over energies obtained after embedding the target of interest in homogenous electric fields of strength equal to $\pm 0.9, \pm 0.3$ and $0.010^{-3}$ a.u. in the $x$-, $y$ - and $z$-directions. The employed basis sets comprise Dunning's correlation consistent polarized valence (cc-pVXZ) basis sets of double (X=D) [20a], triple $(X=T)$ [20a], quadruple $(X=Q)$ [20a], quintuple $(X=5)$ [20a,c] and sextuple $(X=6)$ quality [26, 27], as well as their augmented [20c, 26] and doubly augmented [20c,26] extensions. These basis sets allow extrapolations of electronic energies in clamped nuclei configurations to the limit of an asymptotically complete basis set. Feller's extrapolation formula [28] (eq. 4) has thus been used for the Hartree-Fock energies, while electron correlation energies are extrapolated separately according to the so-called 6(lmn) extension [29] of Schwartz's formula [30] (eq. 5).

$$
\begin{aligned}
& E_{H F}(l)=E_{H F}(\infty)+A e^{-B l} \\
& E_{c o r r}(l)=E_{c o r r}(\infty)+\frac{B}{\left(l+\frac{1}{2}\right)^{4}}+\frac{C}{\left(l+\frac{1}{2}\right)^{6}},
\end{aligned}
$$

where $l$ equals $2,3,4,5,6 \ldots$ for double, triple, quadruple, quintuple, sextuple, .. zeta basis functions, respectively. In the above equations, $E_{H F}(\infty)$ and $E_{c o r r}(\infty)$ stand for the Hartree-Fock and correlation energies in the limit of an asymptotically complete basis set, respectively. These asymptotic values are obtained according to a three-point extrapolation employing results obtained 
using the (d-)aug-cc-pVQZ, (d-)aug-cc-pV5Z and (d-)aug-cc-pV6Z basis sets. Whenever (d-)(aug)cc-pV6Z results are available, a comparison is made for $\mathrm{HF}$ energies obtained according to a recently proposed 2-point extrapolation formula, by A. Karton and J. M. L. Martin [31]:

$$
E_{H F}(l)=E_{H F}(\infty)+A(l+1) e^{-9 \sqrt{l}}
$$

which is expected to be more accurate. Extrapolations to asymptotically complete basis sets are expected to eliminate errors arising from the limitation of finite basis sets.

The static dipole electric dipole polarizabilities of most selected targets $\left(\mathrm{Ne}, \mathrm{CO}, \mathrm{N}_{2}, \mathrm{~F}_{2}, \mathrm{HF}\right.$, $\mathrm{H}_{2} \mathrm{O}, \mathrm{HCN}, \mathrm{C}_{2} \mathrm{H}_{2}$ [ethyne] were thereafter evaluated up to the CCSDTQ(P)/CBS level [i.e. Coupled Cluster Theory along with Single, Double, Triple, Quadruple and perturbative Pentuple electronic excitations in conjunction with an asymptotically complete basis sets (CBS)], by adding to the CCSD(T)/CBS results corrections derived from higher-order Coupled Cluster calculations in conjunction with finite (d)-(aug)-cc-pVXZ basis sets $[\mathrm{X}=\mathrm{D}, \mathrm{T}]$, according to the principles of a Focal Point Analysis [12, 13]. These comprise calculations at the CCSDT [32] or CCSDTQ [33] levels, as well as at the $\operatorname{CCSDT}(\mathrm{Q})$ and $\operatorname{CCSDTQ}(\mathrm{P})$ [34] levels. CCSDTQ/CBS estimates of the polarizabilities of ethylene $\left(\mathrm{C}_{2} \mathrm{H}_{4}\right)$ and acetylene $\left(\mathrm{C}_{2} \mathrm{H}_{6}\right)$ are also presented on the same grounds.

In the sequel, we compare at the $\operatorname{CCSD}(\mathrm{T})$ level purely electronic results for the polarizabilities of $\mathrm{CO}, \mathrm{N}_{2}, \mathrm{~F}_{2}, \mathrm{HF}, \mathrm{H}_{2} \mathrm{O}, \mathrm{HCN}, \mathrm{HCCH}, \mathrm{C}_{2} \mathrm{H}_{4}$, and $\mathrm{C}_{2} \mathrm{H}_{6}$ on geometries that were optimized in a zero field environment, with results that also account for the influence of the field upon the molecular geometries, assuming therefore an adiabatic polarization process within the framework of the BornOppenheimer approximation. For the sake of conciseness, structurally "unrelaxed" and "relaxed" static electric dipole polarizabilities will be from here and henceforth referred to as electronic and adiabatic polarizabilities. In order to compute the latter response properties, geometries have been systematically re-optimized for all selected finite fields at the $\operatorname{CCSD}(\mathrm{T})$ level, along with the augcc-pV5Z and d-aug-cc-pV5Z basis sets. Adiabatic values reported in the sequel under the $\operatorname{CCSD}(\mathrm{T}) /(\mathrm{d})$-aug-cc-VXZ $(\mathrm{X}=\mathrm{Q}, 6)$ entries are therefore the results of further single-point calculations on these re-optimized $\operatorname{CCSD}(\mathrm{T}) /(\mathrm{d})$-aug-cc-V5Z geometries. Further verifications 
employing fully re-optimized geometries for each selected basis set indicate variations by at most 0.0005 a.u. in the static electronic and adiabatic polarizabilities of the hydrogen fluoride (HF) molecule, which demonstrates the convergence of the employed polarized geometries with regards to further improvements of the basis sets, and the numerical consistency of our approach.

All electrons were correlated up to the $\operatorname{CCSD}(\mathrm{T})$ level whereas only valence electrons were correlated at higher levels. Further results obtained for the HF compound at the CCSD(T) level using the aug-cc-pV5Z and the core-corrected aug-cc-pCV5Z basis sets do not deviate by more than 0.006 a.u., which illustrates the overall extremely limited role played by core correlation in polarization processes.

Last but not least, vibrationally averaged results for isotropic electronic polarizabilities (thus regardless of induced geometrical relaxation effects) are obtained by including thermal corrections derived from simulations employing Born-Oppenheimer Molecular Dynamics (BOMD) along with Density Functional Theory [35] in conjunction with the dispersion corrected $\omega$ B97XD exchangecorrelation functional [36] and the aug-cc-pVTZ basis set (except for $\mathrm{C}_{2} \mathrm{H}_{6}$, in which case the employed basis set was aug-cc-pVDZ). In all BOMD simulations, the Bulirsch-Stoer method was used for the integration scheme [37], along with an integration step size of $0.2 f s$, and using a fifthorder polynomial fit in the integration correction scheme. The trajectory step size was most generally set to 0.250 a.u., except for $\mathrm{H}_{2} \mathrm{O}$ and $\mathrm{HF}$, in which case the step size was reduced to 0.100 a.u. . The time average was made on isotropic polarizability values supplied at each point of the calculated BOMD trajectory from analytic $\omega$ B97XD energy gradients. The BOMD calculations were run until the convergence of polarizabilities was ensured within $10^{-2}$ a.u. . This implied runtimes comprised between 2 and 7 ps, corresponding therefore to time averages over 2000 to 5000 structures.

All calculations up to the CCSD(T) level were performed with the MOLPRO 2010.1 package of programs [38] and available Coupled Cluster treatments [39] therein, along with SEWARD [40] for the evaluation of 2-electron integrals. All calculations beyond the $\operatorname{CCSD}(\mathrm{T})$ level were done by 


\section{Results and discussion}

\subsection{Neon}

Static polarizabilities obtained at the $\operatorname{CCSD}(\mathrm{T})$ level and beyond for the neon atom using the ccpVXZ, aug-cc-pVXZ and d-aug-cc-pVXZ basis sets are presented in Table 1, along with values derived from 3-point energy extrapolations based on results obtained with basis sets of triple, quadruple and quintuple [T-Q-5]; or quadruple, quintuple and sextuple [Q-5-6] zeta quality. Due to its spherical symmetry, polarizabilities of this most basic system are fully isotropic. Furthermore, the experimentally inferred values are obviously free of any unwanted geometrical complication.

Known experimental values for the static polarizability of neon range from 2.663 a.u. [45] to $2.667 \pm 0.002$ a.u. [46] and 2.6723 a.u [47]. In spite of the extrapolation to an asymptotically complete basis set, $\operatorname{CCSD}(\mathrm{T})$ results obtained using the non-augmented basis sets appear to severely underestimate the latter value, while the incorporation of single sets of diffuse functions in the basis sets enables us at this level to reproduce experiment within relative accuracies of 0.5 to $0.7 \%$ in the asymptotic CBS limit. Inclusion of double sets of diffuse functions results in further net improvements, with relative accuracies ranging from 0.1 to $0.3 \%$ in the CBS limit. Upon inspecting Table 1, it is also clear that including single and double sets of diffuse functions in the basis set tremendously fasten the convergence of $\operatorname{CCSD}(\mathrm{T})$ results to the CBS limit.

The same observation regarding the influence of the basis set can be made (Figure 1) at lower levels (HF, MP2, MP3, MP4SDQ and CCSD theories). When using non-augmented basis sets (Figure 1a), results obtained at third-order and beyond in the correlation potential are found to have 
practically converged to the Full-CI limit in these basis sets. The sensitivity of the values obtained for polarizabilities upon the correlation treatment severely increases when adding single or double sets of diffuse functions in the basis set. On the other hand, at all theoretical levels, the sensitivity of these results to the cardinal number $(\mathrm{X})$ characterizing the polarization degree of the basis set sharply decreases when single sets of diffuse functions are incorporated, and becomes almost insignificant when the employed basis sets are augmented by double sets of diffuse functions.

Compared with CCSD theory, perturbative triple excitations [T] are found to have a very noticeable influence on the computed polarizabililities (Figure 1). Triple excitations are known indeed to be needed for describing the combined effect of correlation and orbital relaxation [48]. A comparison with higher-level FPA estimates (Table 1) indicates nevertheless that CCSD(T) results should not deviate by more than $10^{-3}$ a.u. (0.03\% accuracy) from the full-CI limit in a given basis set. $\operatorname{CCSD}(\mathrm{T})$ and $\operatorname{CCSDTQ}(\mathrm{P})$ results are almost identical (0.0003 a.u. difference). Our best [CCSDTQ(P)/CBS] estimate for the static polarizability of Ne amounts to 2.6645 a.u., in perfect

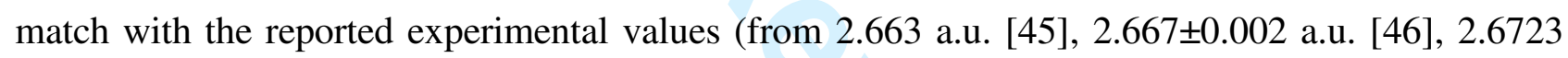
a.u. [47]). Our CCSDTQ(P)/CBS estimate can also be compared with an earlier CC3/d-aug-ccpV6Z value of 2.665 a.u. [49]. Also, Larsen et al report a Full-CI/d-aug-cc-pVDZ value of 2.673 a.u. [50].

\subsection{Convergence of molecular polarizabilitie towards the CCSD $(T) / C B S$ level: general trends.}

Results obtained up to the $\operatorname{CCSD}(\mathrm{T})$ level in conjunction with the d-aug-cc-pVXZ $(X=Q, 5,6, \infty)$ basis sets for the static dipole electronic polarizabilities of $\mathrm{CO}, \mathrm{N}_{2}, \mathrm{H}_{2} \mathrm{O}, \mathrm{C}_{2} \mathrm{H}_{2}$ and $\mathrm{C}_{2} \mathrm{H}_{6}$ are displayed in Figures $2-6$, respectively. It is clear from these figures that the HF and MP2 levels are totally unsuited for quantitative insights into polarizabilities. Unlike neon, convergence becomes quite problematic beyond the MP3 level. The obtained results obtained are virtually unaffected by an increase in the cardinal number $\mathrm{X}$ characterizing the basis set when the latter includes double sets of diffuse functions. In all cases, perturbative triple excitations appear again to have a very 


\subsection{Carbon Monoxide (CO).}

Results obtained from the $\operatorname{CCSD}(\mathrm{T})$ to the $\operatorname{CCSDTQ}(\mathrm{P})$ levels for the static polarizability tensors and isotropic polarizabilities of carbon monoxide are presented in Table 2. Quite naturally, the largest component of this tensor corresponds to the $z$-axis, defining the main rotational axis of the molecule. The experimental value for the isotropic electronic polarizability of $\mathrm{CO}$ is 13.0891 \pm 0.0002 a.u.[51], which compares quite favorably with the best theoretical CCSD(T)/d-augcc-pVœZ value of 13.005 a.u. reported in Table 2. Nevertheless, in view of the convergence of results with regards to the level attained in correlation and the size of the employed basis set, the observed discrepancy of 0.085 a.u. between theory and experiment can only be ascribed to the neglect of the influence of molecular vibrations. Indeed, at the $\operatorname{CSSD}(\mathrm{T})$ level, we note a decrease of the static polarizability from 13.05 to 12.99 a.u. when the basis set evolves from the d-aug-ccpVDZ to the d-aug-cc-pVoZ ones. The latter $\operatorname{CCSD}(\mathrm{T}) / \mathrm{d}$-aug-cc-pVo $\mathrm{Z}$ value appears in turn to be extremely stable when pursuing our quest towards higher-levels in correlation, by means of a Focal Point Analysis in the CBS limit: note in particular that the CCSD(T)/d-aug-cc-pVœZ and estimated $\operatorname{CCSD}(\mathrm{T}) / \mathrm{d}$-aug-cc-pVo $\mathrm{Z}$ values do not differ by more than $\sim 0.033$ a.u. (maximal deviation), indicating convergence of static polarizabilities to the Full-CI/CBS limit within $0.22 \%$ in relative accuracy. 
In an adiabatic depiction, the $\alpha_{\mathrm{zz}}$ component of the static polarizability tensor of $\mathrm{CO}$ is found to be rather sensitive to geometry relaxation effects, whereas purely electronic and structurally relaxed values for the other two components of the tensor $\left(\alpha_{x x}, \alpha_{y y}\right)$ are virtually identical, within $10^{-4}$ a.u., when using basis sets that incorporate doubly augmented sets of diffuse functions. This is to be expected since the $\mathrm{CO}$ bond length does not change much when a field is applied in the $x$ - and $y$ directions, whereas the influence on the geometry is quite noticeable (of the order of $0.5 \mathrm{~m} \AA$ ) when fields ranging from -0.9 to $0.910^{-3}$ a.u. are applied in the $z$-direction (see Table 3). Also, geometrical relaxation effects are found to result into small but detectable increases, of the order of $2.4 \%$, of the $\alpha_{z z}$ component of the polarizability tensor.

\subsection{Nitrogen molecule $\left(N_{2}\right)$.}

In contrast to carbon monoxide, a field applied along the longitudinal (z-) axis of this molecule has an extremely limited influence on its geometry (Table 4). Unsurprisingly therefore, geometrical relaxation in an adiabatic depiction has almost no influence on the static polarizability, see Table 5.

The experimental value for the isotropic electronic polarizability $\bar{\alpha}$ is $11.739 \pm 0.005$ a.u. [46], to compare with our best theoretical CCSDTQ(P)/d-aug-cc-pVœZ estimate of 11.6734 a.u. (0.5\% accuracy). Again, this rather significant underestimation by 0.07 a.u. of the experimental value cannot be ascribed to a deficiency in the treatment of correlation. Indeed, in straightforward analogy with what was reported for $\mathrm{CO}$, decreases by 0.04 to 0.06 a.u. are observed in all components of the polarizability tensor when upgrading the model from $\operatorname{CCSD}(\mathrm{T}) / \mathrm{d}$-aug-cc-pVQZ to CCSD(T)/d-augcc-pVœZ. Comparison with further results beyond the $\operatorname{CCSD}(\mathrm{T}) / \mathrm{d}-\mathrm{aug}-\mathrm{cc}-\mathrm{p} V \propto \mathrm{Z}$ level indicates convergence within 0.01 a.u. (0.08\% relative accuracy) around the Full-CI/CBS limit.

\subsection{Fluoride molecule $\left(F_{2}\right)$.}

Again, decreases by 0.04 to 0.06 a.u. are seen in all components of the polarizability tensor of $\mathrm{F}_{2}$ when upgrading the model from $\operatorname{CCSD}(\mathrm{T}) / \mathrm{d}$-aug-cc-pVQZ to $\operatorname{CCSD}(\mathrm{T}) / \mathrm{d}$-aug-cc-pVœZ (Table 6). 
The experimentally known value for the isotropic static polarizability of $F_{2}$ amounts to $8.27 \pm 0.17$ a.u. [52], to compare with benchmark CBS values converging to $8.32 \pm 0.01$ a.u. from the $\operatorname{CCSD}(\mathrm{T}) / \mathrm{d}-\mathrm{aug}-\mathrm{cc}-\mathrm{pV} \infty \mathrm{Z}$ level and beyond, confirming once more that the Full-CI/CBS limit was almost reached, within $\sim 0.12 \%$. Note that, as with $\mathrm{N}_{2}$ and $\mathrm{CO}$, geometry relaxation in an adiabatic depiction of polarization processes has virtually no influence when the field is set perpendicular to the longitudinal axis, whereas some variations in the molecular response are seen when this axis coincides with the direction of the field.

\subsection{Hydrogen Fluoride (HF)}

For this notoriously difficult compound with regards to static electronic correlation, a comparison with higher-level FPA estimates (Table 7) indicates that $\operatorname{CCSD}(\mathrm{T})$ results have converged within $10^{-2}$ a.u. (0.1\% accuracy) from the full-CI limit in a given basis set. Again, $\operatorname{CCSD}(\mathrm{T})$ and $\operatorname{CCSDTQ}(\mathrm{P})$ results are almost identical (0.0025 a.u. difference). Our best [CCSDTQ(P)/CBS] estimate for the $a_{x x}$ and $a_{z z}$ components of the electronic static polarizability tensor of HF amounts to 5.154 and 6.295 a.u., respectively, to compare with the CC3/d-aug-ccpV5Z values of 5.19 a.u. and 6.33 a.u. published by Hald et al [53]. Values of 5.08 and 6.40 a.u. have been correspondingly obtained on the experimental side [54]. Note the poorer agreement in this case between the theoretical and experimental values, in particular for the longitudinal $\left(a_{z z}\right)$ component, due to the neglect of the outcome of ground state vibrations (see further) in this strongly polarized system.

Whereas most calculations indicate convergence towards 5.15 and 6.30 a.u. in the full-CI/CBS limit, values of 4.287 and 6.210 a.u. have been reported by Larsen et al in [50] for the $\alpha_{x x}$ and $\alpha_{z z}$ components of the static dipole polarizability tensor of HF at the Full-CI/aug-cc-pVDZ level. These values appear to be in quite strong disagreement with our best results as well as with the corresponding available experimental data (5.08 and 6.40 a.u [54]). As is immediately apparent from the CCSD(T)/aug-cc-pVXZ data reported in Table 7, this discrepancy is to be ascribed to the 
basis set employed by Larsen et al [50], which was far too small to enable highly quantitative insight into electronic polarizabilities. Note in particular that our $\operatorname{CCSD}(\mathrm{T}) /$ aug-cc-pVDZ and the above Full-CI/aug-cc-pVDZ values by Larsen et al do not differ by more than 0.02 a.u. .

In the outlook of determinations of adiabatic polarizabilities by means of deflection experiments in inhomogenous fields, it is at last interesting to note that structural relaxation would in this case result into a significant increase of the $a_{z z}$ value by 0.17 a.u. $(\sim+2.7 \%)$, due to a stretching of the HF bond, whereas the $a_{x x}$ and $a_{y y}$ components remain essentially unchanged.

\subsection{Water $\left(\mathrm{H}_{2} \mathrm{O}\right)$}

The $\alpha_{x x}, \alpha_{y y}$ and $\alpha_{z z}$ components of the static polarizability tensor of water were experimentally found [47] to be equal to 9.2, 9.7 and 9.5 a.u., to compare with benchmark CCSD(T)/CBS electronic estimates of 9.18, 9.83, and 9.47 a.u., respectively (Table 8). Maroulis et al obtained correspondingly values of $9.34,9.93$ and 9.58 a.u., upon applying the $\operatorname{CCSD}(\mathrm{T})$ level in conjunction with a finite basis set consisting of 148 contracted Gaussian-type atomic functions [55] upon the experimental equilibrium geometry. More recently, the CC3 approach along with a $(14 s 9 p 3 d \mathrm{f} / 8 s 4 p 3 d)$ contracted basis set led for the same geometry to slightly different values, equal to $9.36,9.94$ and 9.62 a.u., respectively [56]. A comparison of our $\operatorname{CCSD}(\mathrm{T}) / \mathrm{CBS}$ results with higher-level FPA estimates up to the CCSDTQ(P)/CBS level indicates that these results have converged within 1 to $1.510^{-2}$ a.u. (0.1 to $0.15 \%$ accuracy) around the full-CI limit.

Geometrical relaxation effects are significant when the field is aligned onto the $y z$-plane intersecting all atoms of this molecule, with the $z$-direction corresponding to the $\mathrm{C}_{2}$ rotation axis. The $\alpha_{x x}$ component is basically insensitive to geometrical relaxation effects. In contrast, in deflection experiments, geometrical relaxation effects would result into a very noticeable increase of the $\alpha_{y y}$ component, by $\sim 22.7 \%$ at the $\operatorname{CCSD}(\mathrm{T}) / \mathrm{CBS}$ level, due to significant displacements of the two hydrogen atoms, resulting in concerted stretchings or shortenings of the two $\mathrm{OH}$ bonds, as follows: $\mathrm{r}_{\mathrm{OH} 1}[\AA]=0.754185 F_{y}+0.956777 ; \mathrm{r}_{\mathrm{OH} 2}[\AA]=-0.754185 F_{y}+0.956777\left(r^{2}=0.999930\right)$, 
along with non-linear variations in the $\mathrm{HOH}$ bond angle. According to an adiabatic depiction, these relaxation effects result also into a substantial increase of the $\alpha_{z z}$ component, by $7.5 \%$, this time mostly as a result of an opening (closure) of the $\mathrm{HOH}$ bond angle $\left(\theta_{\mathrm{HOH}}\left[^{\circ}\right]=-123.33 F_{z}+104.566\right.$ $\left.\left[r^{2}=0.999999\right]\right)$, along with some stretching of the $\mathrm{OH}$ bond $\left(\mathrm{rOH}[\AA]=0.1152 F_{z}+0.9568\right.$ $\left.\left[r^{2}=0.999864\right]\right)$ and improved (reduced) alignment therefore of the oxygen lone pairs with the field when applying an homogeneous electric field towards the $+z(-z)$ direction [with the oxygen atom intercepting the positive side of the $z$-axis].

\subsection{Hydrogen cyanide (HCN)}

Merely because of the neglect of the increasing influence of ground state vibrations (see further), the agreement between experiment and our best theoretical values rather significantly deteriorates with this compound. Dion et al [57] report experimental values of 13.28 and 21.71 a.u. for the $\alpha_{x x}$ $=\alpha_{y y}$ and $\alpha_{z z}$ components of the static electronic polarizability tensor of $\mathrm{HCN}$, to compare with CCSDTQ(P)/aug-cc-pVœZ estimates equal to 13.85 and 22.10 a.u., respectively. Maroulis et al obtained correspondingly 13.95 a.u. and 22.32 a.u. upon using $\operatorname{CCSD}(\mathrm{T})$ in conjunction with large but finite basis sets [58]. Again, according to FPA estimates at higher-order in correlation, in particular the most diverging CCSDT/aug-cc-pVœZ values, the $\mathrm{CCSD}(\mathrm{T}) / \mathrm{CBS}$ results may nevertheless be regarded as having converged within 0.03 a.u. (0.01\% in relative accuracy) around the Full-CI/CBS limit. The $\operatorname{CCSD}(\mathrm{T})$ and $\operatorname{CCSDTQ}(\mathrm{P})$ values are once more virtually identical, within 0.003 a.u. (0.001\% relative accuracy).

It is worth noticing that, in experimental determinations of adiabatic polarizabilities based on deflection of molecular beams in inhomogenous electric fields, structural relaxation would have a slight but observable influence on the polarization of $\mathrm{HCN}$ when the field is aligned onto the longitudinal axis (z-axis) of this molecule (Table 9). 


\subsection{Ethyne (HCCH).}

From MP2 and beyond, unlike the other compounds so far, and whatever the employed basis set, all theoretical treatments of electron correlation give rise to highly similar values for all components of the polarizability tensor, within a margin of 0.3 a.u. (Figure 5). Comparison of the CCSD(T)/CBS results with higher $\mathrm{CC}$ levels by virtue of a Focal Point Analysis indicates convergence of the theoretical electronic polarizability values within 0.02 a.u. accuracy around the Full-CI/CBS limit (Table 10). At the CCSDTQ(T)/aug-cc-pVœZ level, the isotropic static electronic polarizability of $\mathrm{HCCH}$ (22.476 a.u.) is thus at first glance in a most deceiving agreement with the experimentally known value of 22.96 a.u. [59]. In view of the convergence properties of polarizability values with respect to the employed basis sets and order attained in correlation, the underestimation by $\sim 0.5$ a.u. of the experimental isotropic value is thus most certainly the outcome of the neglect of molecular vibrations (see further).

Note again that in an adiabatic depiction, geometrical relaxation effects have some sizable influence on the inferred polarizabilities when the field is aligned along the longitudinal axis $(z)$ of the molecule (Table 10).

\subsection{Ethylene $\left(\mathrm{C}_{2} \mathrm{H}_{4}\right)$}

Whereas our best FPA [CCSDTQ/CBS] estimates indicate an electronic isotropic static polarizability around $26.65 \pm 0.02$ a.u. for ethylene (Table 11), values ranging from 27.70 a.u. [51] to 27.82 a.u. [60] are known on the experimental side. This rather large discrepancy (more than 1 a.u.) between theory and experiment is certainly not due to a deficiency in our treatment of correlation, but must again be ascribed to an enhancement of the polarizability by vibrations in the ground state (see further). Indeed, a comparison with higher-level FPA estimates for the individual components of the electronic static polarizability tensor indicates that $\operatorname{CCSD}(\mathrm{T})$ results have converged within 1 to $1.510^{-2}$ a.u. (0.04 to $0.06 \%$ accuracy) from the full-CI/CBS limit. Our best [CCSDTQ/CBS] estimates for $a_{x x}, a_{y y}$ and $a_{z z}$ amount to $21.65,24.59$ and 33.72 a.u., to compare 
with CC3/t-aug-cc-pVTZ values equal to 21.93, 24.88 and 34.04 a.u., respectively [53]. The latter values systematically exceed our FPA estimates by 0.2 to 0.3 a.u., essentially because of differences in the employed geometries (the latter CC3 data are indeed based on a high-quality and so-called [61] empirical equilibrium geometry obtained from a combination of experimental rotational constants and CCSD(T)/cc-pVQZ theoretical estimates for vibration-rotation interaction constants).

With regards to experimental determinations of adiabatically relaxed (i.e. on a long time scale) values of the polarizabilities in deflection experiments, it is worth noticing that this time, geometrical relaxation has the strongest influence upon the polarization when the field is aligned along the $x$-axis, i.e. perpendicular to the plane of the molecule. This is to be ascribed to a rather strong curvature of the molecule, in the form of an out-of-place displacement (along the $x$-axis) of the hydrogen atoms, which can be quantified as follows: $\Delta x(\AA)=2.4406 F_{x}\left[r^{2}=1.000\right]$. The $\alpha_{y y}$ or $\alpha_{z z}$ components of the polarizability tensor associated with polarization in plane and perpendicular or parallel to the $\mathrm{C}=\mathrm{C}$ bond are in contrast almost insensitive to geometrical relaxation effects. All in all, structural relaxation effects in such experiments would result into an increase of the effective polarizability by 1 a.u., which seems comparable to the outcome of vibrations in the ground state (see further).

\subsection{Ethane $\left(\mathrm{C}_{2} \mathrm{H}_{6}\right)$.}

At the $\operatorname{CCSD}(\mathrm{T})$ level, components of the electronic polarizability tensor of ethane in its allstaggered $\left(\mathrm{D}_{3 \mathrm{~d}}\right)$ conformation are quite sensitive to the basis set (Table 12): decreases by $\sim 0.1$ a.u. are seen in all components of the tensor when running through the aug-cc-pVXZ series $(X=T, Q, 5$, $\infty)$. Comparison with higher levels in the CBS limit indicates convergence of polarizabilities within 0.03 a.u. (0.1\% relative accuracy) around the Full-CI/CBS values.

In deflection beam experiments, geometrical relaxation would have no significant influence on the polarizability when the electric field is applied along the $\mathrm{C}-\mathrm{C}$ bond ( $z$-axis). In straightforward analogy with ethylene, geometrical relaxation has a stronger influence on the $\alpha_{x x}$ and $\alpha_{y y}$ 
components of the adiabatic polarizability tensor, due to a change in the relative alignment of the C$\mathrm{H}$ bonds with respect to the $x$ - and $y$ axes when a field is applied in these directions.

\subsection{Vibrational corrections to electronic polarizabilities}

Empirical contributions of molecular vibrations at $298 \mathrm{~K}$ to electronic polarizabilities of all target systems are supplied in Table 13, according to a thermal average resorting to Born-Oppenheimer dynamical simulations at the $\omega$ B97XD/aug-cc-pVDZ $\left(\mathrm{C}_{2} \mathrm{H}_{6}\right)$ or $\omega \mathrm{B} 97 \mathrm{XD} /$ aug-cc-pVTZ level, along with calculations at the same level of analytic energy gradients and straightforward evaluation therefore of polarizabilities at each computed point in the BOMD trajectories. The latter corrections are compared with vibrationally averaged results that have been published for a few diatomic $\left(\mathrm{N}_{2}\right.$, $\mathrm{CO}, \mathrm{HF})$ [62] or triatomic species $\left(\mathrm{H}_{2} \mathrm{O}\right)$ [56], according to a spline integration or Gauss-Hermite quadrature over the lowest vibrational quantized state of the (electronic) polarizability function. Although quantum-mechanical and BOMD averages rely on altogether rather different physical grounds, the trends that emerge from the comparison are more than consistent. The larger mobility of the hydrogen atoms results in particular into a clear enhancement of the vibrational correction in systems like $\mathrm{HF}, \mathrm{HCN}$ or $\mathrm{H}_{2} \mathrm{O}$. It is also clear that this vibrational correction increases rapidly with system size. In the $\mathrm{C}_{2} \mathrm{H}_{2 n}$ series $(n=1-3)$, each additional hydrogen atom results very roughly into an increase of the vibrational polarizability correction by $\sim 0.25$ a.u. Quite remarkably, adding these BOMD corrections to our best FPA estimates of the equilibrium electronic polarisabilities (see values in bold in Tables 2, 5-12) enables us to reproduce for all target systems the available experimental isotropic values $[47,51,52,59,63,64,65]$ within $\sim 0.1$ to $\sim 0.2$ a.u. absolute accuracy (i.e. within 1 to $2 \%$ in relative accuracies).

\subsection{Ultimate remarks}

Electronic polarizability and energy results obtained at the HF/(d)-aug-cc-pVœZ level using the 2point extrapolation formula by Karton and Martin [31] are displayed in Table 14, and compared 
with results obtained using Feller's 3-point extrapolation formula. Although extrapolated HF energies are slightly different in the CBS limit, the 2- and 3-point energy extrapolation formula give virtually identical results for the ultimately inferred polarizabilities (within 0.0000 to 0.0024 a.u.). When extrapolating results obtained using basis sets up to the aug-cc-pV5Z one, the 3-point Feller's approach seems more reliable, an observation that is in line with conclusions drawn by Karton and Martin [31].

\section{Conclusions}

Estimating the second derivative of the energy with respect to applied electric fields according to the principles of a Focal Point Analysis has enabled us to calculate the electric static polarizability tensor and related isotropic polarizabilities of a variety of molecules at the level of CCSDTQ(P) [or CCSDTQ] theory in conjunction with asymptotically complete basis sets. The obtained values are almost insensitive to the cardinal number characterizing the employed Dunning's correlation consistent polarized valence basis sets when these include double sets of diffuse functions. Compared with results obtained at lower levels in correlation (MP2, MP3, MP4SDQ, CCSD), perturbative triple excitations at the $\operatorname{CCSD}(\mathrm{T})$ level are found in general to have a quite significant influence, and to result into noticeable increases of electronic polarizabilities (by up to $\sim 0.2$ a.u.). Nevertheless, the $\operatorname{CCSD}(\mathrm{T})$ level was found to provide a very viable approach for highly quantitative computations of electronic polarizabilities, most often within $\sim 0.1 \%$ in relative accuracy compared with much higher-level CC treatments that appear to have practically converged to the Full-CI limit. The main residual source of errors in our analysis pertains to the influence of thermally induced ro-vibrational motions in the electronic ground state, which has been more empirically evaluated on the grounds of classical trajectory simulations employing BornOppenheimer Molecular Dynamics (BOMD) along with Density Functional Theory and a dispersion corrected exchange correlation functional. Adding such BOMD estimates for the vibrational contributions enables us to ultimately reproduce the experimental isotropic electronic 
polarizabilities of all chosen targets within 1 to $2 \%$ accuracy, a most respectable achievement which makes us believe that the physics embodied in experimental determinations of static polarizabilities through e.g. refraction measurements has been correctly grasped.

Comparison has been made with so-called adiabatic polarizability values, accounting for the relaxation of clamped nuclei configurations in the framework of the Born-Oppenheimer approximation, in the outlook of long-time scale polarization experiments. Structural relaxation effects were found occasionally to result into an increase of static polarizabilities by a few $\%$. Such effects should be in particular detectable in experimental determinations of the polarizability of water and ethylene based on beam deflection in inhomogeneous electric fields.

\section{Acknowledgements}

All calculations presented in this work have been performed on a Compaq ES47 work station at Hasselt University, Belgium. For this work we also used the infrastructure of the VSC Flemish Supercomputer Center, funded by the Hercules foundation and the Flemish Government department EWI. This work has been supported by the FWO-Vlaanderen, the Flemish branch of the Belgian National Science Foundation, and by the BijzonderOnderzoeksFonds (BOF: special research fund) at Hasselt Univeity. M. S. D and B. H. especially acknowledge financial support from a Research Program of the Research Foundation - Flanders (FWO_Vlaanderen; project number G.0350.09 N, entitled 'From orbital imaging to quantum similarity in momentum space'. R. M. was the recipient of a one-month scholarship in summer 2010 after the completion of his third bachelor year in physics at Hasselt University, including a training stay of 10 weeks in the research group of Theoretical Chemistry and Molecular Modeling. He is currently studying physics at the master level at the Katholieke Universiteit Leuven. 


\section{References}

[1] (a) K. Jankowski, in Methods in Computational Chemistry, edited by S. Wilson (Plenum, New York, 1992); Vol. 5; (b) R.D. Amos, Adv. Chem. Phys., 67, 989 (1987); (c) C. F. Dykstra, S. Y. Liu, D. J. Malik, Adv. Chem. Phys., 75, 37 (1989)]. A most fundamental example is the static polarizability [(a) M. P. Bogaard and B. J. Orr, in Molecular Structure and Properties, edited by A. D. Buckingham (Butterworths, London, 1975); (b) A. D. Buckingham, in Intermolecular Interactions: From Diatomics to Biopolymers, edited by B. Pullman (Wiley, New York, 1978), p. 1

[2] M. Schwartz, Principles of electrodynamics, ch. 10.1-10.4, p. 321-330. Dover Publications, inc. (1996)

[3] J. F. Ward and C. K. Miller, Phys. Rev. A 19, 826 (1979)

[4] (a) P. W. Fowler, Theory and Calculation of Molecular Properties, Annual Report C (Royal Society of Chemistry, London, 1987), p. 3; (b) A. A. Hasanein, Adv. Chem. Phys. 85, 415 (1993); (c) A. Hinchliffe, Ab Initio Determination of Molecular Properties (Adam Hilger, Bristol, 1987); (d) C. E. Dykstra, Ab Initio Calculation of the Structures and Properties of Molecules (Elsevier, Amsterdam, 1988); (e) D. M. Bishop, Adv. Quantum Chem. 25, 1 (1994) (ScienceDirect); (f) J. Olsen and P. Jørgensen, in Modern Electronic Structure Theory, edited by D. R. Yarkony (World Scientific, London, 1995), p. 857; (g) Y. Luo, H. Ågren, P. Jørgensen, and K. V. Mikkelsen, Adv. Quantum Chem. 26, 165 (1995); (h) M. Nakano and K. Yamaguchi, in Trends in Chemical Physics, Vol. 5 (Research Trends, Trivandrum, 1997); (i) D. Pugh, in Chemical Modeling: Applications and Theory (Vol. 1), edited by A. Hinchliffe (The Royal Society of Chemistry, London, 2000), p. 1; (j) D. M. Bishop and P. Norman, in Handbook of Advanced Electronic and Photonic Materials, edited by H. S. Nalwa (Academic, San Diego, 2000); (k) B. Champagne and B. Kirtman, in Handbook of Advanced Electronic and Photonic Materials, edited by H. S. Nalwa (Academic, San Diego, 2000).

[5] (a) A. Proutiere, Mol. Phys. 65, 499 (1988); (b) L. Frommold, Adv. Chem. Phys. 46, 1 (1981); (c) C.L. Cheng, D.S.N. Murphy, G.L.D. Ritchie, Aus. J. Chem. 25, 1301 (1978); (d) W. S. Gelbart, Adv. Chem. Phys. 26, 1 (1974); (e) H. G. Kuball, R. Göb, Z. Phys. Chem. 63, 251 (1969).

[6] L. L. Boyle, A. D. Buckingham, R. L. Disch, D. A. Dummur, J. Chem. Phys. 45, 1318 (1966).

[7] (a) R. S. Finn, J. F. Ward, Phys. Rev. Lett. 26, 285 (1971); (b) R. S. Finn, J. F. Ward, J. Chem. Phys. 60, 454 (1974); (c) I.S. Bigio, J. F. Ward, Phys. Rev. A, 9, 35 (1974); (d) K. M. Leung, J. F. Ward, and B. J. Orr, Phys. Rev. A 9, 2440 (1974).

[8] S. Heitz, S. Weidauer, B. Rosenow, A. Hese, J. Chem. Phys. 96, 976 (1992).

[9] (a) A. Ballard, K. Bonin, J. Louderback, J. Chem. Phys. 113, 5732 (2000); (b) M. B.

Knickelbein, J. Chem. Phys. 115, 5957 (2001); (c) D. Rayane, I. Compagnon, R. Antoine, M. Broyer, Ph. Dugourd, R. Labastie, J.M. L’Hermite, A. Le Padellec, G. Durand, F. Calvo, F. Spiegelman, A. R. Allouche, J. Chem. Phys. 116, 10730 (2002).

[10] (a) H-J. Werner, W. Meyer, Mol. Phys. 31, 855 (1976); (b) A. J. Sadlej, Theoret Chim Acta, 79, 123 (1991).

[11] N. Bloembergen, Nonlinear Optics (Benjamin, New York, 1965); D. C. Hanna, M. A. Yuratich, and D. Cotter, Nonlinear Optics of Free Atoms and Molecules (Springer, Berlin, 1979); Y. R. Shen, Principles of Nonlinear Optics (Wiley, New York, 1984); J.-M. André, J. Delhalle, J.-L. Brédas, Quantum Chemistry Aided Design of Organic Polymers, World Scientific Publishing, 1991, Singapore.

[12] (a) A. L. L. East and W. D. Allen, J. Chem. Phys., 99, 4638 (1993); (b) N. L. Allinger, J. T. Fermann, W. D. Allen, and H. F. Schaefer III, J. Chem. Phys. 106, 5143 (1997); (c) A. G. Császár, W. D. Allen, and H. F. Schaefer III, J. Chem. Phys., 108, 9751 (1998); (d) A. G. Császár, G. Tarczay, M. L. Leininger, O. L. Polyansky, and W. D. Allen, in Spectroscopy From 
Space, edited J. Demaison and K. Sarka (Kluwer, Dordrecht, 2001) p. 317; (e) A. G. Császár, V. Szalay, and M. L. Senent, J. Chem. Phys. 120, 1203 (2004); (f) E. Czinki and A. G. Császár, Chemistry (Weinheim, Ger.) 9, 1008 (2003); (g) J. Demaison, J. Liévin, A. G. Császár, and C. Guttle, J. Phys. Chem. A 112, 4477 (2008); (h) O. S. Bokareva and V. A. Bataev, Int. J. Quantum Chem. 108, 2719 (2008); (i) T. Szidarovszky, G. Czakó, and A. G. Császár, Mol. Phys. 107, 761 (2009); (j) J. J. Wilke, M. C. Lind, H. F. Schaefer III, A. G. Császár, and A. D. Allen, J. Chem. Theory Comput. 5, 1511 (2009); (k) R. M. Balabin, Chem. Phys. Lett., 479, 195 (2009.

[13] M. S. Deleuze, L. Claes, E. S. Kryachko and J. -P. François, J. Chem. Phys., 119, 3106, (2003); B. Hajgató, M. S. Deleuze, D. J. Tozer, F. De Proft, J. Chem. Phys, 129, 084308 (2008); B. Hajgató, D. Szieberth, P. Geerlings, F. De Proft, and M. S. Deleuze, J. Chem. Phys. 131, 224321 (2009).

[14] (a) A. Szabo, N. S. Ostlund, Modern Quantum Chemistry, McGraw Hill, New York (1989); (b) T. Helgacker, P. Jørgensen, J. Olsen, Molecular Electronic Structure Theory, John Wiley \& Sons, Chichester (2000).

[15] (a) K. Raghavachari, G. W. Trucks, J. A. Pople, M. Head-Gordon, Chem. Phys. Lett. 157, 479 (1989); (b) R. J. Bartlett, J. D. Watts, S. A. Kucharski, J. Noga, Chem. Phys. Lett 165, 513 (1990); (c) J. F. Stanton, Chem. Phys. Lett. 281, 130 (1997).

[16] (a) C. J. Jameson, P. W. Fowler, J. Chem. Phys. 85, 3432 (1986); (b) P. G. Jasien and G. Fitzgerald, J. Chem. Phys. 93, 2554 (1990); (c) F. Sim and D. R. Salahub, Int. J. Quantum Chem. 43, 463 (1992); (d) J. Guan, P. Duffy, J. T. Carter, D. P. Chong, K. C. Casida, M. E. Casida, and M. Wrinn, J. Chem. Phys. 98, 4753 (1993); (e) D. A. Dixon and N. Matsuzawa, J. Phys. Chem. 98, 3967 (1994); (f) N. Matsuzawa and D. A. Dixon, J. Phys. Chem. 98, 2545 (1994); (g) J. Guan, M. E. Casida, A. M. Köster, and D. R. Salahub, Phys. Rev. B 52, 2184 (1995); (h) S. A. C. McDowell, R. D. Amos, and N. C. Handy, Chem. Phys. Lett. 235, 1 (1995); (i) N. Matsuzawa, M. Ata, and D. A. Dixon, J. Phys. Chem. 99, 7698 (1995).

[17] (a) T. Helgaker, E. Uggerud, and H. J. A. Jensen, Chem. Phys. Lett., 173 (1990) 145; (b) E. Uggerud and T. Helgaker, J. Am. Chem. Soc., 114 (1992) 4265; (c) K. Bolton, W. L. Hase, and G. H. Peslherbe, in Modern Methods for Multidimensional Dynamics Computation in Chemistry, Ed. D. L. Thompson (World Scientific, Singapore, 1998) 143.

[18] (a) J. Oddershede, Adv. Quantum Chem. 11, 275 (1978); (b) J. Oddershede, P. Jørgensen, D. L. Yeager, Comput. Phys. Rep. 2, 33, (1984); (c) K. L. Bak et al, J. Chem. Phys. 112, 4173 (2000).

[19] (a) M. Deleuze, M.J. Packer, B.T. Pickup, D.J. Wilton, J. Chem. Phys. 102, 6128 (1995); (b) M. S. Deleuze, B.T. Pickup, Int. J. Quantum Chem. 63, 465 (1997); (c) M.S. Deleuze, B.T. Pickup, D.A. Wilton, Int. J. Quantum Chem. 77, 625 (2000).

[20] (a) T. H. Dunning, Jr., J. Chem. Phys. 90, 1007 (1989); (b) R. A. Kendall, T. H. Dunning, Jr., R. J. Harrison, J. Chem. Phys. 96, 6796 (1992); (c) D. E. Woon, T. H. Dunning, Jr, J. Chem. Phys. 100, 2975 (1994).

[21] C. Møller, M. S. Plesset, Phys Rev. 46, 618 (1934).

[22] M. Head-Gordon, J. A. Pople, M. J. Frisch, Chem. Phys. Lett. 153, 503 (1988).

[23] R. Krishnan, J. A. Pople, Int. J. Quantum Chem. 14, 91 (1978).

[24] G. D. Purvis III, R. J. Bartlett, J. Chem. Phys. 76, 1910 (1982).

[25] H. H. Jaffé, M. Orchin, Symmetry in Chemistry, John Wiley \& Sons, New York (1965).

[26] A. K. Wilson, T. van Mourik, T. H. Dunning, Jr., J. Mol. Struct.: THEOCHEM 388, 339 (1998)

[27] K. A. Peterson, D. E. Woon, T. H. Dunning, Jr., J. Chem. Phys. 100, 7410 (1994).

[28] (a) D. Feller, J. Chem. Phys. 96, 6104 (1992); (b) ibid 98, 7059 (1993).

[29] J. M. L. Martin, in Energetics of Stable Molecules and Reactive Intermediates, NATO ASI Symposium Series, edited by M. E. Mirrasda Piedade and K. K. Irikura, Kluwer, Dordrecht (1999).

[30] C. Schwartz, in Methods in Computational Physics, edited by B. J. Alder (Academic, New York, 1963). 
[31] A. Karton, J.M.L. Martin, Theor. Chem. Acc. 115, 330 (2006).

[32] (a) J. Noga and R.J. Bartlett, J. Chem. Phys. 86, 7041 (1987), Erratum J. Chem. Phys. 89, 3401 (1988); (b) G.E. Scuseria and H.F. Schaefer III, Chem. Phys. Letters 152, 382 (1988).

[33] (a) N. Oliphant and L. Adamowicz, J. Chem. Phys. 95, 6645 (1991); (b) S.A. Kucharski and R.J. Bartlett, J. Chem. Phys. 97, 4282 (1992).

[34] Y.J. Bomble, M. Kállay, J. Gauss, and J.F. Stanton, J. Chem. Phys. 123, 054101 (2005).

[35] R. G. Parr, W. Yang; Density Functional Theory of Atoms and Molecules; Oxford University Press: New York, 1989.

[36] J.-D. Chai and M. Head-Gordon, Phys. Chem. Chem. Phys., 10, 6615 (2008).

[37] (a) Bulirsch, R. and Stoer, J.; in Introduction to Numerical Analysis. New York: SpringerVerlag, 1991. (b) Press, W. H.; Flannery, B. P.; Teukolsky, S. A.; and Vetterling, W. T.; Richardson Extrapolation and the Bulirsch-Stoer Method. in Numerical Recipes in FORTRAN: The Art of Scientific Computing, 2nd ed., pp. 718-725 (edited by Cambridge University Press, Cambridge, England, 1992).

[38] MOLPRO, version 2010.1, a package of ab initio programs, H.-J. Werner, P. J. Knowles, F. R. Manby, M. Schütz, P. Celani, G. Knizia, T. Korona, R. Lindh, A. Mitrushenkov, G. Rauhut, T. B. Adler, R. D. Amos, A. Bernhardsson, A. Berning, D. L. Cooper, M. J. O. Deegan, A. J. Dobbyn, F. Eckert, E. Goll, C. Hampel, A. Hesselmann, G. Hetzer, T. Hrenar, G. Jansen, C. Köppl, Y. Liu, A. W. Lloyd, R. A. Mata, A. J. May, S. J. McNicholas, W. Meyer, M. E. Mura, A. Nicklass, P. Palmieri, K. Pflüger, R. Pitzer, M. Reiher, T. Shiozaki, H. Stoll, A. J. Stone, R. Tarroni, T. Thorsteinsson, M. Wang, and A. Wolf, see http://www.molpro.net.

[39] C. Hampel, K. Peterson, and H.-J. Werner, Chem. Phys. Lett. 190, 1 (1992) and references therein. The program to compute the perturbative triples corrections has been developed by $\mathrm{M}$. J. O. Deegan and P. J. Knowles, Chem. Phys. Lett. 227, 321 (1994).

[40] R. Lindh, U. Ryu, and B. Liu, J. Chem. Phys. 95, 5889 (1991).

[41] MRCC is a string-based many-body program, written by M. Kállay. (a) M. Kállay and P. R. Surján, J. Chem. Phys. 1152945 (2001); (b) M. Kállay and J. Gauss, J. Chem. Phys. 123 214105 (2005); see http://www.mrcc.hu.

[42] (a) D. L. Bunker, Meth. Comp. Phys., 10 (1971) 287; (b) L. M. Raff and D. L. Thompson, in Theory of Chemical Reaction Dynamics, Ed. M. Baer (CRC, Boca Raton, FL, 1985); (c) Advances in Classical Trajectory Methods, Vol. 1-3, Ed. W. L. Hase (JAI, Stamford, CT, 1991); (d) D. L. Thompson, in Encyclopedia of Computational Chemistry, Ed. P. v. R. Schleyer, N. L. Allinger, P. A. Kollman, T. Clark, H. F. Schaefer III, J. Gasteiger, and P. R. Schreiner (Wiley, Chichester, 1998) 3056.

[43] (a) W. Chen, W. L. Hase, and H. B. Schlegel, Chem. Phys. Lett., 228, 436 (1994); (b) J. M. Millam, V. Bakken, W. Chen, W. L. Hase, and H. B. Schlegel, J. Chem. Phys., 111, 3800 (1999); (c) X. Li, J. M. Millam, and H. B. Schlegel, J. Chem. Phys., 113, 10062 (2000). Selection of the initial conditions: W. L. Hase, R. J. Duchovic, X. Hu, A. Komornicki, K. F. Lim, D.-H. Lu, G. H. Peslherbe, K. N. Swamy, S. R. V. Linde, A. Varandas, H. Wang, and R. J. Wolfe, "VENUS96: A General Chemical Dynamics Computer Program," QCPE, 16 (1996) 671.

[44] Gaussian 09, Revision B.01, M. J. Frisch, G. W. Trucks, H. B. Schlegel, G. E. Scuseria, M. A. Robb, J. R. Cheeseman, G. Scalmani, V. Barone, B. Mennucci, G. A. Petersson, H. Nakatsuji, M. Caricato, X. Li, H. P. Hratchian, A. F. Izmaylov, J. Bloino, G. Zheng, J. L. Sonnenberg, M. Hada, M. Ehara, K. Toyota, R. Fukuda, J. Hasegawa, M. Ishida, T. Nakajima, Y. Honda, O. Kitao, H. Nakai, T. Vreven, J. A. Montgomery, Jr., J. E. Peralta, F. Ogliaro, M. Bearpark, J. J. Heyd, E. Brothers, K. N. Kudin, V. N. Staroverov, R. Kobayashi, J. Normand, K. Raghavachari, A. Rendell, J. C. Burant, S. S. Iyengar, J. Tomasi, M. Cossi, N. Rega, J. M. Millam, M. Klene, J. E. Knox, J. B. Cross, V. Bakken, C. Adamo, J. Jaramillo, R. Gomperts, R. E. Stratmann, O. Yazyev, A. J. Austin, R. Cammi, C. Pomelli, J. W. Ochterski, R. L. Martin, K. Morokuma, V. G. Zakrzewski, G. A. Voth, P. Salvador, J. J. Dannenberg, S. Dapprich, A. D. Daniels, Ö. Farkas, J. 
B. Foresman, J. V. Ortiz, J. Cioslowski, and D. J. Fox, Gaussian, Inc., Wallingford CT, 2009. [45] P. R. Teachout, R.T. Pack, At. Data, 3, 195 (1971).

[46] R. H. Orcutt, R. H. Cole, J. Chem. Phys 46, 697 (1967).

[47] G.L. Pollack, D.R. Stump, Electromagnetism, pp186-201; Addison Wesley, (2002).

[48] H. J. A. Jensen, P. Jørgensen, T. Helgaker, Chem. Phys. Lett. 162, 355 (1989).

[49] K. Hald, F. Pawlowski, P. Jørgensen, J. Chem. Phys., 118, 1292 (2003).

[50] H. Larsen, J. Olsen, C. Hättig, and P. Jørgensen, O. Christiansen, J. Gauss, J. Chem. Phys. 111, 1917 (1999).

[51] G. A. Parker, R. T. Pack, J. Chem. Phys. 64, 2010 (1976).

[52] G. Maroulis, C. Makris, Computing Letters 2, 131 (2006).

[53] K. Hald, F. Pawlowski, P. Jørgensen, J. Chem. Phys., 118, 1292 (2003).

[54] J.S. Muenster, J. Chem. Phys. 56, 5409 (1972).

[55] G. Maroulis, Chem. Phys. Lett., 289, 403 (1998).

[56] G. Avila, J. Chem. Phys. 122, 144310 (2005).

[57] C. M. Dion, A. Keller, O. Atabek, A. D. Bandrauk, Phys. Rev. A 59, 1382 (1998).

[58] G. Maroulis, C. Pouchan, Phys. Rev. A 57, 2440 (1998).

[59] T. N. Olney, N. M. Cann, G. Cooper, C. E. Brion, Chem. Phys. 223, 59 (1997).

[60] R. Tammer, W. Hüttner, Mol. Phys. 83, 579 (1994).

[61] F. Pawłowski, P. Jørgensen, J. Olsen, F. Hegelung, T. Helgaker, J. Gauss, K. L. Bak, J. F. Stanton, J. Chem. Phys. 116, 6482 (2002).

[62] O. Christiansen, C. Hättig, J. Gauss, J. Chem. Phys. 109, 4745 (1998).

[63] W. F. Murphy, J. Chem. Phys. 67, 5866 (1977).

[64] M. A. Spackman, J. Phys. Chem. 93, 7594 (1989).

[65] Static polarizability from the Kerr effect [R. Tammer, W. Hüttner, Mol. Phys. 83, 579 (1994)]. 
Table 1: Polarizability of neon at the CCSD(T) level of theory, and beyond (FPA results; all values are in a.u.)

\begin{tabular}{|c|c|c|c|}
\cline { 2 - 4 } \multicolumn{1}{c|}{ Method/Basis } & cc-pVXZ & aug-cc-pVXZ & d-aug-cc-pVXZ \\
\hline $\operatorname{CCSD}(\mathrm{T}) / \mathrm{X}=\mathrm{T}$ & 1.0303 & 2.4183 & 2.6858 \\
\hline $\mathrm{CCSD}(\mathrm{T}) / \mathrm{X}=\mathrm{Q}$ & 1.5151 & 2.5900 & 2.6743 \\
\hline $\mathrm{CCSD}(\mathrm{T}) / \mathrm{X}=5$ & 1.8553 & 2.6382 & 2.6641 \\
\hline $\mathrm{CCSD}(\mathrm{T}) / \mathrm{X}=6$ & 2.1309 & 2.6500 & 2.6630 \\
\hline $\mathrm{CCSD}(\mathrm{T}) / \mathrm{X}=\infty^{\mathrm{a}}$ & 2.1255 & 2.6624 & 2.6532 \\
\hline $\mathrm{CCSD}(\mathrm{T}) / \mathrm{X}=\infty^{\mathrm{b}}$ & 2.2569 & 2.6561 & 2.6648 \\
\hline $\mathrm{CCSDT}^{\mathrm{c}} / \mathrm{X}=\infty^{\mathrm{b}}$ & 2.2567 & 2.6564 & 2.6652 \\
\hline $\left.\mathrm{CCSDT}^{\mathrm{b}} \mathrm{Q}\right)^{\mathrm{d} / \mathrm{X}=\infty^{\mathrm{b}}}$ & 2.2569 & 2.6566 & 2.6656 \\
\hline $\mathrm{CCSDTQ}^{\mathrm{e}} / \mathrm{X}=\infty^{\mathrm{b}}$ & 2.2569 & 2.6564 & 2.6654 \\
\hline $\mathrm{CCSDTQ}^{\mathrm{f}}(\mathrm{P})^{\mathrm{f}} / \mathrm{X}=\infty^{\mathrm{b}}$ & 2.2568 & 2.6563 & $\mathbf{2 . 6 6 4 5}$ \\
\hline
\end{tabular}

a: 3-point extrapolation employing $X=T, Q, 5$;

b: 3-point extrapolation employing $\mathrm{X}=\mathrm{Q}, 5,6$;

c: FPA estimate, using $E[C C S D T /(d)-(a u g)-c c-p V \infty Z]=E[C C S D(T) /(d)-(a u g)-c c-p V \infty Z]+$ $E[(\mathrm{CCSDT} /(\mathrm{d})-($ aug $)$-cc-pVTZ) $]-E[(\mathrm{CCSD}(\mathrm{T}) /(\mathrm{d})-(\mathrm{aug})-\mathrm{cc}-\mathrm{pVTZ})]$.

$\mathrm{d}$ : FPA estimate, using $E[\operatorname{CCSDT}(\mathrm{Q}) /(\mathrm{d})-)($ aug $)-\mathrm{cc}-\mathrm{pV} \infty \mathrm{Z}]=E[\mathrm{CCSD}(\mathrm{T}) /(\mathrm{d})-(\mathrm{aug})-\mathrm{cc}-\mathrm{pV} \infty \mathrm{Z}]+$ $E[(\operatorname{CCSDT}(\mathrm{Q}) /(\mathrm{d})-(\mathrm{aug})-\mathrm{cc}-\mathrm{pVTZ})]-E[(\mathrm{CCSD}(\mathrm{T}) /(\mathrm{d})-(\mathrm{aug})-\mathrm{cc}-\mathrm{pVTZ})]$.

e: FPA estimate, using $E[C C S D T Q /(d)-($ aug $)-c c-p V \infty Z]=E[C C S D(T) /(d)-($ aug $)-c c-p V \infty Z]+$ $E[(\mathrm{CCSDTQ} /(\mathrm{d})-(\mathrm{aug})-\mathrm{cc}-\mathrm{pVDZ})]-E[(\mathrm{CCSD}(\mathrm{T}) /(\mathrm{d})-(\mathrm{aug}) \mathrm{cc}-\mathrm{pVDZ})]$.

f: FPA estimate, using $E[C C S D T(P) /(d)-($ aug $)-c c-p V \infty Z]=E[C C S D(T) /(d)-(a u g)-c c-p V \infty Z]+$ $E[(\operatorname{CCSDTQ}(\mathrm{P}) /(\mathrm{d})-(\mathrm{aug})-\mathrm{cc}-\mathrm{pVDZ})]-E[(\operatorname{CCSD}(\mathrm{T}) /(\mathrm{d})-(\mathrm{aug})-\mathrm{cc}-\mathrm{pVDZ})]$ 
Table 2: Polarizability tensor $\left(\alpha_{\mathrm{xx}}=\alpha_{\mathrm{yy}}, \alpha_{\mathrm{zz}}\right)$ and isotropic polarizability $(\bar{\alpha})$ of CO at the $\operatorname{CCSD}(\mathrm{T})$ level, and beyond (FPA results; all values are in a.u.)

\begin{tabular}{|c|c|c|c|c|}
\hline \multirow{2}{*}{$\alpha_{x x}$} & \multicolumn{2}{|c|}{ adiabatic } & \multicolumn{2}{c|}{ electronic } \\
\cline { 2 - 5 } & aug-cc-pVxZ & d-aug-cc-pVxZ & aug-cc-pVxZ & d-aug-cc-pVxZ \\
\hline $\mathrm{CCSD}(\mathrm{T}) / \mathrm{X}=\mathrm{Q}$ & 11.8587 & 11.8580 & 11.8518 & 11.8580 \\
\hline $\mathrm{CCSD}(\mathrm{T}) / \mathrm{X}=5$ & 11.8454 & 11.8403 & 11.8286 & 11.8403 \\
\hline $\mathrm{CCSD}(\mathrm{T}) / \mathrm{X}=6$ & 11.8226 & 11.8266 & 11.8254 & 11.8266 \\
\hline $\mathrm{CCSD}(\mathrm{T}) / \mathrm{X}=\infty^{\mathrm{a}}$ & 11.7771 & 11.8045 & 11.8253 & 11.8045 \\
\hline $\mathrm{CCSDT}^{\mathrm{b}} / \mathrm{X}=\infty^{\mathrm{a}}$ & & & 11.8171 & 11.7959 \\
\hline $\left.\mathrm{CCSDT}^{\mathrm{Q}} \mathrm{Q}\right)^{\mathrm{c}} / \mathrm{X}=\infty^{\mathrm{a}}$ & & & 11.8372 & 11.8165 \\
\hline $\mathrm{CCSDTQ}^{\mathrm{d}} / \mathrm{X}=\infty^{\mathrm{a}}$ & & & 11.8419 & 11.8114 \\
\hline $\mathrm{CCSDTQ}^{\mathrm{P}}(\mathrm{P})^{\mathrm{e}} / \mathrm{X}=\infty^{\mathrm{a}}$ & & & 11.8430 & $\mathbf{1 1 . 8 1 2 2}$ \\
\hline
\end{tabular}

\begin{tabular}{|c|c|c|c|c|}
\hline \multirow{2}{*}{$\alpha_{z z}$} & \multicolumn{2}{|c|}{ adiabatic } & \multicolumn{2}{c|}{ electronic } \\
\cline { 2 - 5 } & aug-cc-pVxZ & d-aug-cc-pVxZ & aug-cc-pVxZ & d-aug-cc-pVxZ \\
\hline $\mathrm{CCSD}(\mathrm{T}) / \mathrm{X}=\mathrm{Q}$ & 15.8420 & 15.8320 & 15.4336 & 15.4266 \\
\hline $\mathrm{CCSD}(\mathrm{T}) / \mathrm{X}=5$ & 15.7475 & 15.7585 & 15.3913 & 15.3970 \\
\hline $\mathrm{CCSD}(\mathrm{T}) / \mathrm{X}=6$ & 15.7422 & 15.7439 & 15.3818 & 15.3800 \\
\hline $\mathrm{CCSD}(\mathrm{T}) / \mathrm{X}=\infty^{\mathrm{a}}$ & 15.7677 & 15.7416 & 15.3783 & 15.3557 \\
\hline $\mathrm{CCSDT}^{\mathrm{b}} / \mathrm{X}=\infty^{\mathrm{a}}$ & & & 15.3558 & 15.3327 \\
\hline $\mathrm{CCSDT}(\mathrm{Q})^{\mathrm{c}} / \mathrm{X}=\infty^{\mathrm{a}}$ & & & 15.4111 & 15.3884 \\
\hline $\mathrm{CCSDTQ}^{\mathrm{d}} / \mathrm{X}=\infty^{\mathrm{a}}$ & & & 15.4004 & 15.3778 \\
\hline $\mathrm{CCSDTQ}^{\mathrm{P}}(\mathrm{P})^{\mathrm{e}} / \mathrm{X}=\infty^{\mathrm{a}}$ & & & 15.4117 & $\mathbf{1 5 . 3 8 9 1}$ \\
\hline
\end{tabular}

\begin{tabular}{|c|c|c|c|c|}
\cline { 2 - 5 } \multicolumn{1}{c|}{} & \multicolumn{2}{c|}{ adiabatic } & \multicolumn{2}{c|}{ electronic } \\
\cline { 2 - 5 } \multicolumn{1}{c|}{} & aug-cc-pVxZ & d-aug-cc-pVxZ & aug-cc-pVxZ & d-aug-cc-pVxZ \\
\hline $\mathrm{CCSD}(\mathrm{T}) / \mathrm{X}=\mathrm{Q}$ & 13.1865 & 13.1826 & 13.0457 & 13.0475 \\
\hline $\mathrm{CCSD}(\mathrm{T}) / \mathrm{X}=5$ & 13.1461 & 13.1464 & 13.0161 & 13.0259 \\
\hline $\mathrm{CCSD}(\mathrm{T}) / \mathrm{X}=6$ & 13.1291 & 13.1324 & 13.0109 & 13.0111 \\
\hline $\mathrm{CCSD}(\mathrm{T}) / \mathrm{X}=\infty^{\mathrm{a}}$ & 13.1073 & 13.1169 & 13.0096 & 12.9882 \\
\hline $\mathrm{CCSDT}^{\mathrm{b}} / \mathrm{X}=\infty^{\mathrm{a}}$ & & & 12.9967 & 12.9748 \\
\hline $\left.\mathrm{CCSDT}^{\mathrm{n}} \mathrm{Q}\right)^{\mathrm{c}} / \mathrm{X}=\infty^{\mathrm{a}}$ & & & 13.0285 & 13.0072 \\
\hline $\mathrm{CCSDTQ}^{\mathrm{d}} / \mathrm{X}=\infty^{\mathrm{a}}$ & & & 13.0214 & 13.0002 \\
\hline $\left.\mathrm{CCSDTQ}^{\mathrm{a}} \mathrm{P}\right)^{\mathrm{e}} / \mathrm{X}=\infty^{\mathrm{a}}$ & & & 13.0259 & $\mathbf{1 3 . 0 0 4 5}$ \\
\hline
\end{tabular}

a: 3-point extrapolation employing $\mathrm{X}=\mathrm{Q}, 5,6$;

b: FPA estimate, using $E[C C S D T /(d)$-aug-cc-pVœZ $]=E[C C S D(T) /(d)-a u g-c c-p V \infty Z]+$ 
$E[(\mathrm{CCSDT} /(\mathrm{d})$-aug-cc-pVTZ) $]-E[(\mathrm{CCSD}(\mathrm{T}) /(\mathrm{d})$-aug-cc-pVTZ) $]$.

c: FPA estimate, using $E[\operatorname{CCSDT}(\mathrm{Q}) /(\mathrm{d})$-aug-cc-p $\infty \propto \mathrm{Z}]=E[\mathrm{CCSD}(\mathrm{T}) /(\mathrm{d})$-aug-cc-pV $\infty \mathrm{Z}]+$ $E[(\mathrm{CCSDT}(\mathrm{Q}) /(\mathrm{d})$-aug-cc-pVTZ) $]-E[(\operatorname{CCSD}(\mathrm{T}) /(\mathrm{d})$-aug-cc-pVTZ) $]$.

d: FPA estimate, using $E[C C S D T Q /(d)$-aug-cc-pVœZ $]=E[C C S D(T) /(d)$-aug-cc-pV $\infty \mathrm{Z}]+$ $E[(\mathrm{CCSDTQ} /(\mathrm{d})$-aug-cc-pVDZ) $]-E[(\mathrm{CCSD}(\mathrm{T}) /(\mathrm{d})$-aug-cc-pVDZ) $]$.

e: FPA estimate, using $E[C C S D T(P) /(d)-a u g-c c-p V \infty Z]=E[C C S D(T) /(d)-a u g-c c-p V \infty Z]+$ $E[(\mathrm{CCSDTQ}(\mathrm{P}) /(\mathrm{d})$-aug-cc-pVDZ) $]-E[(\mathrm{CCSD}(\mathrm{T}) /(\mathrm{d})$-aug-cc-pVDZ) $]$ 
Table 3: Evolution of the internuclear distance in the CO molecule (in $\AA$ ) in function of the applied external field (CCSD(T) results)

\begin{tabular}{|c|c|c|c|}
\cline { 3 - 4 } \multicolumn{2}{c|}{} & aug-cc-pV5Z & d-aug-cc-pV5Z \\
\hline \multirow{3}{*}{$F_{x}$} & 0.0000 & 1.1273395 & 1.1272168 \\
\cline { 2 - 4 } & 0.0003 & 1.1273395 & 1.1272168 \\
\cline { 2 - 4 } & 0.0009 & 1.1273399 & 1.1272168 \\
\hline \multirow{3}{*}{$F_{z}$} & 0.0009 & 1.1270821 & 1.1269593 \\
\cline { 2 - 4 }$\left(F_{y}=F_{z}=0\right)$ & 0.0003 & 1.1272532 & 1.1271304 \\
\cline { 2 - 4 } & 0.0000 & 1.1273395 & 1.1272168 \\
\cline { 2 - 4 } & -0.0003 & 1.1274262 & 1.1273034 \\
\cline { 2 - 4 } & -0.0009 & 1.1276011 & 1.1274783 \\
\hline
\end{tabular}


Table 4: Evolution of the internuclear distance in the $\mathrm{N}_{2}$ molecule (in $\AA$ ) in function of the applied external field (CCSD(T) results)

\begin{tabular}{|c|c|c|c|}
\cline { 3 - 4 } \multicolumn{2}{c|}{} & aug-cc-pV5Z & d-aug-cc-pV5Z \\
\hline \multirow{3}{*}{$F_{x}$} & 0.0000 & 1.0967346 & 1.0965869 \\
\cline { 2 - 4 } & 0.0003 & 1.0967346 & 1.0965870 \\
\cline { 2 - 4 } & 0.0009 & 1.0967351 & 1.0965874 \\
\hline \multirow{2}{*}{$\left.F_{z}=0\right)$} & 0.0000 & 1.0967346 & 1.0965869 \\
\cline { 2 - 4 }$\left(F_{y}=F_{z}=0\right)$ & 0.0003 & 1.0967347 & 1.0965871 \\
\cline { 2 - 4 } & 0.0009 & 1.0967361 & 1.0965884 \\
\hline
\end{tabular}


Table 5: Polarizability tensor $\left(\alpha_{\mathrm{xx}}=\alpha_{\mathrm{yy}}, \alpha_{\mathrm{zz}}\right)$ and isotropic polarizability $(\bar{\alpha})$ of $\mathrm{N}_{2}$ at the $\operatorname{CCSD}(\mathrm{T})$ level, and beyond (FPA results; all values are in a.u.)

\begin{tabular}{|c|c|c|c|c|}
\hline \multirow{2}{*}{$\alpha_{\mathrm{xx}}$} & \multicolumn{2}{|c|}{ adiabatic } & \multicolumn{2}{c|}{ electronic } \\
\cline { 2 - 5 } & aug-cc-pVxZ & d-aug-cc-pVxZ & aug-cc-pVxZ & d-aug-cc-pVxZ \\
\hline $\mathrm{CCSD}(\mathrm{T}) / \mathrm{X}=\mathrm{Q}$ & 10.2023 & 10.2050 & 10.1920 & 10.1934 \\
\hline $\mathrm{CCSD}(\mathrm{T}) / \mathrm{X}=5$ & 10.1727 & 10.1724 & 10.1730 & 10.1726 \\
\hline $\mathrm{CCSD}(\mathrm{T}) / \mathrm{X}=6$ & 10.1633 & 10.1635 & 10.1641 & 10.1635 \\
\hline $\mathrm{CCSD}(\mathrm{T}) / \mathrm{X}=\infty^{\mathrm{a}}$ & 10.1570 & 10.1570 & 10.1547 & 10.1520 \\
\hline $\mathrm{CCSDT}^{\mathrm{b}} / \mathrm{X}=\infty^{\mathrm{a}}$ & & & 10.1516 & 10.1476 \\
\hline $\mathrm{CCSDT}(\mathrm{Q})^{\mathrm{c}} / \mathrm{X}=\infty^{\mathrm{a}}$ & & & 10.1661 & 10.1617 \\
\hline $\mathrm{CCSDTQ}^{\mathrm{d}} / \mathrm{X}=\infty^{\mathrm{a}}$ & & & 10.1610 & 10.1577 \\
\hline $\mathrm{CCSDTQ}^{\mathrm{P}}(\mathrm{P})^{\mathrm{e}} / \mathrm{X}=\infty^{\mathrm{a}}$ & & & 10.1631 & $\mathbf{1 0 . 1 5 9 3}$ \\
\hline
\end{tabular}

\begin{tabular}{|c|c|c|c|c|}
\hline \multirow{2}{*}{$\alpha_{z z}$} & \multicolumn{2}{|c|}{ adiabatic } & \multicolumn{2}{c|}{ electronic } \\
\cline { 2 - 5 } & aug-cc-pVxZ & d-aug-cc-pVxZ & aug-cc-pVxZ & d-aug-cc-pVxZ \\
\hline $\mathrm{CCSD}(\mathrm{T}) / \mathrm{X}=\mathrm{Q}$ & 14.7928 & 14.8021 & 14.7632 & 14.7687 \\
\hline $\mathrm{CCSD}(\mathrm{T}) / \mathrm{X}=5$ & 14.7341 & 14.7359 & 14.7348 & 14.7366 \\
\hline $\mathrm{CCSD}(\mathrm{T}) / \mathrm{X}=6$ & 14.7244 & 14.7251 & 14.7266 & 14.7250 \\
\hline $\mathrm{CCSD}(\mathrm{T}) / \mathrm{X}=\infty^{\mathrm{a}}$ & 14.7234 & 14.7276 & 14.7173 & 14.7126 \\
\hline $\mathrm{CCSDT}^{\mathrm{b}} / \mathrm{X}=\infty^{\mathrm{a}}$ & & & 14.7461 & 14.7397 \\
\hline $\mathrm{CCSDT}(\mathrm{Q})^{\mathrm{c}} / \mathrm{X}=\infty^{\mathrm{a}}$ & & & 14.7052 & 14.6993 \\
\hline $\mathrm{CCSDTQ}{ }^{\mathrm{d}} / \mathrm{X}=\infty^{\mathrm{a}}$ & & & 14.7091 & 14.7027 \\
\hline $\mathrm{CCSDTQ}^{\mathrm{P}}(\mathrm{P})^{\mathrm{e}} / \mathrm{X}=\infty^{\mathrm{a}}$ & & & 14.7079 & $\mathbf{1 4 . 7 0 1 4}$ \\
\hline
\end{tabular}

\begin{tabular}{|c|c|c|c|c|}
\hline \multirow{2}{*}{$\bar{\alpha}$} & \multicolumn{2}{|c|}{ adiabatic } & \multicolumn{2}{c|}{ electronic } \\
\cline { 2 - 5 } & aug-cc-pVxZ & d-aug-cc-pVxZ & aug-cc-pVxZ & d-aug-cc-pVxZ \\
\hline $\mathrm{CCSD}(\mathrm{T}) / \mathrm{X}=\mathrm{Q}$ & 11.7324 & 11.7374 & 11.7157 & 11.7185 \\
\hline $\mathrm{CCSD}(\mathrm{T}) / \mathrm{X}=5$ & 11.6932 & 11.6936 & 11.6936 & 11.6939 \\
\hline $\mathrm{CCSD}(\mathrm{T}) / \mathrm{X}=6$ & 11.6837 & 11.6840 & 11.6849 & 11.6840 \\
\hline $\mathrm{CCSD}(\mathrm{T}) / \mathrm{X}=\infty^{\mathrm{a}}$ & 11.6791 & 11.6805 & 11.6756 & 11.6722 \\
\hline $\mathrm{CCSDT}^{\mathrm{b}} / \mathrm{X}=\infty^{\mathrm{a}}$ & & & 11.6831 & 11.6783 \\
\hline $\mathrm{CCSDT}^{\mathrm{Q}}(\mathrm{Q})^{\mathrm{c}} / \mathrm{X}=\infty^{\mathrm{a}}$ & & & 11.6791 & 11.6742 \\
\hline $\mathrm{CCSDTQ}{ }^{\mathrm{d}} / \mathrm{X}=\infty^{\mathrm{a}}$ & & & 11.6772 & 11.6727 \\
\hline $\mathrm{CCSDTQ}^{\mathrm{P}}(\mathrm{P})^{\mathrm{e}} / \mathrm{X}=\infty^{\mathrm{a}}$ & & & 11.6782 & $\mathbf{1 1 . 6 7 3 4}$ \\
\hline
\end{tabular}

a: 3-point extrapolation employing $\mathrm{X}=\mathrm{Q}, 5,6$;

b: FPA estimate, using $E[C C S D T /(d)$-aug-cc-pVœZ $]=E[C C S D(T) /(d)-a u g-c c-p V \infty Z]+$ 
$E[(\mathrm{CCSDT} /(\mathrm{d})$-aug-cc-pVTZ) $]-E[(\mathrm{CCSD}(\mathrm{T}) /(\mathrm{d})$-aug-cc-pVTZ) $]$.

c: FPA estimate, using $E[\operatorname{CCSDT}(\mathrm{Q}) /(\mathrm{d})$-aug-cc-p $\infty \propto \mathrm{Z}]=E[\mathrm{CCSD}(\mathrm{T}) /(\mathrm{d})$-aug-cc-pV $\infty \mathrm{Z}]+$ $E[(\mathrm{CCSDT}(\mathrm{Q}) /(\mathrm{d})$-aug-cc-pVTZ) $]-E[(\operatorname{CCSD}(\mathrm{T}) /(\mathrm{d})$-aug-cc-pVTZ) $]$.

d: FPA estimate, using $E[C C S D T Q /(d)$-aug-cc-pVœZ $]=E[C C S D(T) /(d)$-aug-cc-pV $\infty \mathrm{Z}]+$ $E[(\mathrm{CCSDTQ} /(\mathrm{d})$-aug-cc-pVDZ) $]-E[(\mathrm{CCSD}(\mathrm{T}) /(\mathrm{d})$-aug-cc-pVDZ) $]$.

e: FPA estimate, using $E[C C S D T(P) /(d)-a u g-c c-p V \infty Z]=E[C C S D(T) /(d)-a u g-c c-p V \infty Z]+$ $E[(\mathrm{CCSDTQ}(\mathrm{P}) /(\mathrm{d})$-aug-cc-pVDZ) $]-E[(\mathrm{CCSD}(\mathrm{T}) /(\mathrm{d})$-aug-cc-pVDZ) $]$ 
Table 6: Polarizability tensor $\left(\alpha_{\mathrm{xx}}=\alpha_{\mathrm{yy}}, \alpha_{\mathrm{zz}}\right)$ and isotropic polarizability $(\bar{\alpha})$ of $\mathrm{F}_{2}$ at the $\operatorname{CCSD}(\mathrm{T})$ level and beyond (FPA results; all values are in a.u.)

\begin{tabular}{|c|c|c|c|c|}
\hline \multirow{2}{*}{$\alpha_{\mathrm{xx}}$} & \multicolumn{2}{|c|}{ adiabatic } & \multicolumn{2}{c|}{ electronic } \\
\cline { 2 - 5 } & aug-cc-pVxZ & d-aug-cc-pVxZ & aug-cc-pVxZ & d-aug-cc-pVxZ \\
\hline $\mathrm{CCSD}(\mathrm{T}) / \mathrm{X}=\mathrm{Q}$ & 6.3111 & 6.3890 & 6.3111 & 6.3890 \\
\hline $\mathrm{CCSD}(\mathrm{T}) / \mathrm{X}=5$ & 6.3352 & 6.3716 & 6.3352 & 6.3716 \\
\hline $\mathrm{CCSD}(\mathrm{T}) / \mathrm{X}=6$ & 6.3427 & 6.3600 & 6.3427 & 6.3600 \\
\hline $\mathrm{CCSD}(\mathrm{T}) / \mathrm{X}=\infty^{\mathrm{a}}$ & 6.3441 & 6.3465 & 6.3441 & 6.3432 \\
\hline $\mathrm{CCSDT}^{\mathrm{b}} / \mathrm{X}=\infty^{\mathrm{a}}$ & & & 6.3450 & 6.3460 \\
\hline $\mathrm{CCSDT}^{\mathrm{Q}}(\mathrm{Q})^{\mathrm{c}} / \mathrm{X}=\infty^{\mathrm{a}}$ & & & 6.3626 & 6.3697 \\
\hline $\mathrm{CCSDTQ}^{\mathrm{d}} / \mathrm{X}=\infty^{\mathrm{a}}$ & & & 6.3593 & $\mathbf{6 . 3 6 3 6}$ \\
\hline $\mathrm{CCSDTQ}^{\mathrm{P}}(\mathrm{P})^{\mathrm{e}} / \mathrm{X}=\infty^{\mathrm{a}}$ & & & 6.3604 & - \\
\hline
\end{tabular}

\begin{tabular}{|c|c|c|c|c|}
\hline \multirow{2}{*}{$\alpha_{z z}$} & \multicolumn{2}{|c|}{ adiabatic } & \multicolumn{2}{c|}{ electronic } \\
\cline { 2 - 5 } & aug-cc-pVxZ & d-aug-cc-pVxZ & aug-cc-pVxZ & d-aug-cc-pVxZ \\
\hline $\mathrm{CCSD}(\mathrm{T}) / \mathrm{X}=\mathrm{Q}$ & 12.2501 & 12.3264 & 12.2285 & 12.3048 \\
\hline $\mathrm{CCSD}(\mathrm{T}) / \mathrm{X}=5$ & 12.2754 & 12.2842 & 12.2467 & 12.2842 \\
\hline $\mathrm{CCSD}(\mathrm{T}) / \mathrm{X}=6$ & 12.2538 & 12.2680 & 12.2669 & 12.2761 \\
\hline $\mathrm{CCSD}(\mathrm{T}) / \mathrm{X}=\infty^{\mathrm{a}}$ & 12.1937 & 12.2492 & 12.2955 & 12.2659 \\
\hline $\mathrm{CCSDT}^{\mathrm{b}} / \mathrm{X}=\infty^{\mathrm{a}}$ & & & 12.3352 & 12.3030 \\
\hline $\mathrm{CCSDT}(\mathrm{Q})^{\mathrm{c}} / \mathrm{X}=\infty^{\mathrm{a}}$ & & & 12.2374 & 12.2088 \\
\hline $\mathrm{CCSDTQ}{ }^{\mathrm{d}} / \mathrm{X}=\infty^{\mathrm{a}}$ & & & 12.2523 & $\mathbf{1 2 . 2 2 5 4}$ \\
\hline $\mathrm{CCSDTQ}^{\mathrm{P}}(\mathrm{P})^{\mathrm{e}} / \mathrm{X}=\infty^{\mathrm{a}}$ & & & 12.2508 & - \\
\hline
\end{tabular}

\begin{tabular}{|c|c|c|c|c|}
\hline \multirow{2}{*}{$\bar{\alpha}$} & \multicolumn{2}{|c|}{ adiabatic } & \multicolumn{2}{|c|}{ electronic } \\
\hline & aug-cc-pVxZ & d-aug-cc-pVxZ & aug-cc-pVxZ & d-aug-cc-pVxZ \\
\hline $\operatorname{CCSD}(\mathrm{T}) / \mathrm{X}=\mathrm{Q}$ & 8.2908 & 8.3682 & 8.2836 & 8.3610 \\
\hline $\operatorname{CCSD}(\mathrm{T}) / \mathrm{X}=5$ & 8.3153 & 8.3424 & 8.3057 & 8.3425 \\
\hline $\operatorname{CCSD}(\mathrm{T}) / \mathrm{X}=6$ & 8.3131 & 8.3293 & 8.3174 & 8.3320 \\
\hline $\operatorname{CCSD}(\mathrm{T}) / \mathrm{X}=\infty^{\mathrm{a}}$ & 8.2940 & 8.3118 & 8.3279 & 8.3174 \\
\hline $\operatorname{CCSDT}^{\mathrm{b}} / \mathrm{X}=\infty^{\mathrm{a}}$ & & & 8.3417 & 8.3316 \\
\hline $\operatorname{CCSDT}(Q)^{\mathrm{c}} / \mathrm{X}=\infty^{\mathrm{a}}$ & & & 8.3208 & 8.3161 \\
\hline $\operatorname{CCSDTQ}^{\mathrm{d}} / \mathrm{X}=\infty^{\mathrm{a}}$ & & & 8.3237 & 8.3176 \\
\hline $\operatorname{CCSDTQ}(\mathrm{P})^{\mathrm{e}} / \mathrm{X}=\infty^{\mathrm{a}}$ & & & 8.3239 & - \\
\hline
\end{tabular}

a: 3-point extrapolation employing $X=Q, 5,6$;

b: FPA estimate, using $E[C C S D T /(d)-a u g-c c-p V \infty Z]=E[C C S D(T) /(d)-a u g-c c-p V \infty Z]+$ 
$E[(\mathrm{CCSDT} /(\mathrm{d})$-aug-cc-pVTZ) $]-E[(\mathrm{CCSD}(\mathrm{T}) /(\mathrm{d})$-aug-cc-pVTZ) $]$.

c: FPA estimate, using $E[\operatorname{CCSDT}(\mathrm{Q}) /(\mathrm{d})$-aug-cc-p $\infty \propto \mathrm{Z}]=E[\mathrm{CCSD}(\mathrm{T}) /(\mathrm{d})$-aug-cc-pV $\infty \mathrm{Z}]+$ $E[(\mathrm{CCSDT}(\mathrm{Q}) /(\mathrm{d})$-aug-cc-pVTZ) $]-E[(\operatorname{CCSD}(\mathrm{T}) /(\mathrm{d})$-aug-cc-pVTZ) $]$.

d: FPA estimate, using $E[C C S D T Q /(d)$-aug-cc-pVœZ $]=E[C C S D(T) /(d)$-aug-cc-pV $\infty \mathrm{Z}]+$ $E[(\mathrm{CCSDTQ} /(\mathrm{d})$-aug-cc-pVDZ) $]-E[(\mathrm{CCSD}(\mathrm{T}) /(\mathrm{d})$-aug-cc-pVDZ) $]$.

e: FPA estimate, using $E[C C S D T(P) /(d)-a u g-c c-p V \infty Z]=E[C C S D(T) /(d)-a u g-c c-p V \infty Z]+$ $E[(\mathrm{CCSDTQ}(\mathrm{P}) /(\mathrm{d})$-aug-cc-pVDZ) $]-E[(\mathrm{CCSD}(\mathrm{T}) /(\mathrm{d})$-aug-cc-pVDZ) $]$ 
Table 7: Polarizability tensor $\left(\alpha_{\mathrm{xx}}=\alpha_{\mathrm{yy}}, \alpha_{\mathrm{zz}}\right)$ of HF at the CCSD(T) level and beyond (FPA results; all values are in a.u.)

\begin{tabular}{|c|c|c|c|c|}
\hline \multirow{2}{*}{$\alpha_{\mathrm{xx}}$} & \multicolumn{2}{|c|}{ adiabatic } & \multicolumn{2}{c|}{ electronic } \\
\cline { 2 - 5 } & aug-cc-pVxZ & d-aug-cc-pVxZ & aug-cc-pVxZ & d-aug-cc-pVxZ \\
\hline $\mathrm{CCSD}(\mathrm{T}) / \mathrm{X}=\mathrm{D}$ & - & - & 4.2762 & - \\
\hline $\mathrm{CCSD}(\mathrm{T}) / \mathrm{X}=\mathrm{T}$ & - & - & 4.8708 & - \\
\hline $\mathrm{CCSD}(\mathrm{T}) / \mathrm{X}=\mathrm{Q}$ & 5.0669 & 5.1888 & 5.0669 & 5.1888 \\
\hline $\mathrm{CCSD}(\mathrm{T}) / \mathrm{X}=5$ & 5.1159 & 5.1680 & 5.1159 & 5.1680 \\
\hline $\mathrm{CCSD}(\mathrm{T}) / \mathrm{X}=6$ & 5.1366 & 5.1600 & 5.1366 & 5.1600 \\
\hline $\mathrm{CCSD}(\mathrm{T}) / \mathrm{X}=\infty^{\mathrm{a}}$ & 5.1473 & 5.1516 & 5.1473 & 5.1516 \\
\hline $\mathrm{CCSDT}^{\mathrm{b}} / \mathrm{X}=\infty^{\mathrm{a}}$ & - & - & 5.1499 & 5.1541 \\
\hline $\mathrm{CCSDT}^{\mathrm{y}}(\mathrm{Q})^{\mathrm{c}} / \mathrm{X}=\infty^{\mathrm{a}}$ & - & - & 5.1546 & 5.1601 \\
\hline $\mathrm{CCSDTQ}^{\mathrm{d}} / \mathrm{X}=\infty^{\mathrm{a}}$ & - & - & 5.1529 & 5.1574 \\
\hline $\mathrm{CCSDTQ}^{\mathrm{y}}(\mathrm{P})^{\mathrm{e}} / \mathrm{X}=\infty^{\mathrm{a}}$ & - & - & $\mathbf{5 . 1 5 1 2}$ & $\mathbf{5 . 1 5 4 1}$ \\
\hline
\end{tabular}

\begin{tabular}{|c|c|c|c|c|}
\hline \multirow{2}{*}{$\alpha_{z z}$} & \multicolumn{2}{|c|}{ adiabatic } & \multicolumn{2}{c|}{ electronic } \\
\cline { 2 - 5 } & aug-cc-pVxZ & d-aug-cc-pVxZ & aug-cc-pVxZ & d-aug-cc-pVxZ \\
\hline $\mathrm{CCSD}(\mathrm{T}) / \mathrm{X}=\mathrm{D}$ & - & - & 6.1890 & - \\
\hline $\mathrm{CCSD}(\mathrm{T}) / \mathrm{X}=\mathrm{T}$ & - & - & 6.2968 & - \\
\hline $\mathrm{CCSD}(\mathrm{T}) / \mathrm{X}=\mathrm{Q}$ & 6.4729 & 6.4872 & 6.3011 & 6.3141 \\
\hline $\mathrm{CCSD}(\mathrm{T}) / \mathrm{X}=5$ & 6.4627 & 6.4687 & 6.2940 & 6.2996 \\
\hline $\mathrm{CCSD}(\mathrm{T}) / \mathrm{X}=6$ & 6.4622 & 6.4642 & 6.2917 & 6.2947 \\
\hline $\mathrm{CCSD}(\mathrm{T}) / \mathrm{X}=\infty^{\mathrm{a}}$ & 6.4630 & 6.4617 & 6.2882 & 6.2903 \\
\hline $\mathrm{CCSDT}^{\mathrm{b}} / \mathrm{X}=\infty^{\mathrm{a}}$ & - & - & 6.2912 & 6.2931 \\
\hline $\left.\mathrm{CCSDT}^{\mathrm{y}} \mathrm{Q}\right)^{\mathrm{c}} / \mathrm{X}=\infty^{\mathrm{a}}$ & - & - & 6.2986 & 6.3007 \\
\hline $\mathrm{CCSDTQ}^{\mathrm{d}} / \mathrm{X}=\infty^{\mathrm{a}}$ & - & - & 6.2963 & 6.2982 \\
\hline $\mathrm{CCSDTQ}^{\mathrm{y}}(\mathrm{P})^{\mathrm{e}} / \mathrm{X}=\infty^{\mathrm{a}}$ & - & - & $\mathbf{6 . 2 9 3 6}$ & $\mathbf{6 . 2 9 5 1}$ \\
\hline
\end{tabular}

a: 3-point extrapolation employing $\mathrm{X}=\mathrm{Q}, 5,6$;

b: FPA estimate, using $E[C C S D T /(d)$-aug-cc-pV $\infty \mathrm{Z}]=E[C C S D(T) /(d)-a u g-c c-p V \infty Z]+$ $E[(\mathrm{CCSDT} /(\mathrm{d})$-aug-cc-pVTZ) $]-E[(\mathrm{CCSD}(\mathrm{T}) /(\mathrm{d})$-aug-cc-pVTZ) $]$.

c: FPA estimate, using $E[C C S D T(Q) /(d)-a u g-c c-p V \infty Z]=E[C C S D(T) /(d)-a u g-c c-p V \infty Z]+$ $E[(\mathrm{CCSDT}(\mathrm{Q}) /(\mathrm{d})$-aug-cc-pVTZ) $]-E[(\mathrm{CCSD}(\mathrm{T}) /(\mathrm{d})$-aug-cc-pVTZ) $]$.

d: FPA estimate, using $E[C C S D T Q /(d)$-aug-cc-pVœZ] $=E[C C S D(T) /(d)$-aug-cc-pV $\infty \mathrm{Z}]+$ $E[(\mathrm{CCSDTQ} /(\mathrm{d})$-aug-cc-pVDZ) $]-E[(\mathrm{CCSD}(\mathrm{T}) /(\mathrm{d})$-aug-cc-pVDZ) $]$.

e: FPA estimate, using $E[C C S D T(P) /(d)$-aug-cc-pV $\infty \mathrm{Z}]=E[C C S D(T) /(d)$-aug-cc-pVoZ $]+$ $E[(\operatorname{CCSDTQ}(\mathrm{P}) /(\mathrm{d})$-aug-cc-pVDZ) $]-E[(\operatorname{CCSD}(\mathrm{T}) /(\mathrm{d})$-aug-cc-pVDZ) $]$ 
Table 8: Polarizability tensor $\left(\alpha_{\mathrm{xx}}, \alpha_{\mathrm{yy}}, \alpha_{\mathrm{zz}}\right)$ and isotropic polarizability $(\bar{\alpha})$ of $\mathrm{H}_{2} \mathrm{O}$ at the $\operatorname{CCSD}(\mathrm{T})$ level and beyond (FPA results; all values are in a.u.)

\begin{tabular}{|c|c|c|c|c|}
\hline \multirow{2}{*}{$\alpha_{\mathrm{xx}}$} & \multicolumn{2}{|c|}{ adiabatic } & \multicolumn{2}{|c|}{ electronic } \\
\hline & aug-cc-pVxZ & d-aug-cc-pVxZ & aug-cc-pVxZ & d-aug-cc-pVxZ \\
\hline $\operatorname{CCSD}(\mathrm{T}) / \mathrm{X}=\mathrm{Q}$ & 9.1440 & 9.2514 & 9.1402 & 9.2470 \\
\hline $\operatorname{CCSD}(\mathrm{T}) / \mathrm{X}=5$ & 9.1689 & 9.2147 & 9.1702 & 9.2149 \\
\hline $\operatorname{CCSD}(\mathrm{T}) / \mathrm{X}=6$ & 9.1842 & 9.2048 & 9.1820 & 9.2015 \\
\hline $\operatorname{CCSD}(\mathrm{T}) / \mathrm{X}=\infty^{\mathrm{a}}$ & 9.1966 & 9.1988 & 9.1851 & 9.1862 \\
\hline $\operatorname{CCSDT}^{\mathrm{b}} / \mathrm{X}=\infty^{\mathrm{a}}$ & & & 9.1865 & \\
\hline $\operatorname{CCSDT}(Q)^{\mathrm{c}} / \mathrm{X}=\infty^{\mathrm{a}}$ & 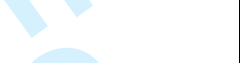 & & 9.2082 & \\
\hline $\operatorname{CCSDTQ}^{\mathrm{d}} / \mathrm{X}=\infty^{\mathrm{a}}$ & ) & & 9.2009 & \\
\hline $\operatorname{CCSDTQ}(\mathrm{P})^{\mathrm{e}} / \mathrm{X}=\infty^{\mathrm{a}}$ & $P$ & & 9.1977 & \\
\hline
\end{tabular}

\begin{tabular}{|c|c|c|c|c|}
\hline \multirow{2}{*}{$\alpha_{y y}$} & \multicolumn{2}{|c|}{ adiabatic } & \multicolumn{2}{c|}{ Electronic } \\
\cline { 2 - 5 } & aug-cc-pVxZ & d-aug-cc-pVxZ & aug-cc-pVxZ & d-aug-cc-pVxZ \\
\hline $\mathrm{CCSD}(\mathrm{T}) / \mathrm{X}=\mathrm{Q}$ & 12.1351 & 12.1373 & 9.8553 & 9.8648 \\
\hline $\mathrm{CCSD}(\mathrm{T}) / \mathrm{X}=5$ & 12.0807 & 12.0885 & 9.8392 & 9.8444 \\
\hline $\mathrm{CCSD}(\mathrm{T}) / \mathrm{X}=6$ & 12.0806 & 12.0748 & 9.8323 & 9.8378 \\
\hline $\mathrm{CCSD}(\mathrm{T}) / \mathrm{X}=\infty^{\mathrm{a}}$ & 12.0980 & 12.0642 & 9.8223 & 9.8320 \\
\hline $\mathrm{CCSDT}^{\mathrm{b}} / \mathrm{X}=\infty^{\mathrm{a}}$ & & & 9.8245 & \\
\hline $\left.\mathrm{CCSDT}^{\mathrm{Q}} \mathrm{Q}\right)^{\mathrm{c}} / \mathrm{X}=\infty^{\mathrm{a}}$ & & & 9.8380 & \\
\hline $\mathrm{CCSDTQ}^{\mathrm{d}} / \mathrm{X}=\infty^{\mathrm{a}}$ & & & 9.8345 & \\
\hline $\left.\mathrm{CCSDTQ}^{\mathrm{P}} \mathrm{P}\right)^{\mathrm{e}} / \mathrm{X}=\infty^{\mathrm{a}}$ & & & $\mathbf{9 . 8 3 2 0}$ & \\
\hline
\end{tabular}

\begin{tabular}{|c|c|c|c|c|}
\hline \multirow{2}{*}{$\alpha_{z z}$} & \multicolumn{2}{|c|}{ adiabatic } & \multicolumn{2}{c|}{ electronic } \\
\cline { 2 - 5 } & aug-cc-pVxZ & d-aug-cc-pVxZ & aug-cc-pVxZ & d-aug-cc-pVxZ \\
\hline $\mathrm{CCSD}(\mathrm{T}) / \mathrm{X}=\mathrm{Q}$ & 10.1828 & 10.2608 & 9.4417 & 9.5189 \\
\hline $\mathrm{CCSD}(\mathrm{T}) / \mathrm{X}=5$ & 10.1992 & 10.2356 & 9.4654 & 9.4965 \\
\hline $\mathrm{CCSD}(\mathrm{T}) / \mathrm{X}=6$ & 10.2235 & 10.2391 & 9.4707 & 9.4880 \\
\hline $\mathrm{CCSD}(\mathrm{T}) / \mathrm{X}=\infty^{\mathrm{a}}$ & 10.2629 & 10.2559 & 9.4677 & 9.4786 \\
\hline $\mathrm{CCSDT}^{\mathrm{b}} / \mathrm{X}=\infty^{\mathrm{a}}$ & & & 9.4681 & \\
\hline $\left.\mathrm{CCSDT}^{\mathrm{Q}} \mathrm{Q}\right)^{\mathrm{c}} / \mathrm{X}=\infty^{\mathrm{a}}$ & & & 9.4852 & \\
\hline $\mathrm{CCSDTQ}^{\mathrm{d}} / \mathrm{X}=\infty^{\mathrm{a}}$ & & & 9.4814 & \\
\hline $\left.\mathrm{CCSDTQ}^{\mathrm{P}} \mathrm{P}\right)^{\mathrm{e}} / \mathrm{X}=\infty^{\mathrm{a}}$ & & & $\mathbf{9 . 4 7 8 6}$ & \\
\hline
\end{tabular}

a: 3-point extrapolation employing $\mathrm{X}=\mathrm{Q}, 5,6$;

b: FPA estimate, using $E[C C S D T /(d)$-aug-cc-pVœZ $]=E[C C S D(T) /(d)-a u g-c c-p V \infty Z]+$ $E[(\mathrm{CCSDT} /(\mathrm{d})$-aug-cc-pVTZ) $]-E[(\mathrm{CCSD}(\mathrm{T}) /(\mathrm{d})$-aug-cc-pVTZ) $]$. 
c: FPA estimate, using $E[C C S D T(Q) /(d)-$ aug-cc-p $\vee \infty Z]=E[C C S D(T) /(d)-a u g-c c-p V \infty Z]+$ $E[(\operatorname{CCSDT}(\mathrm{Q}) /(\mathrm{d})$-aug-cc-pVTZ) $]-E[(\operatorname{CCSD}(\mathrm{T}) /(\mathrm{d})$-aug-cc-pVTZ)].

d: FPA estimate, using $E[C C S D T Q /(d)$-aug-cc-pV $\infty Z]=E[C C S D(T) /(d)$-aug-cc-pV $\infty Z]+$ $E[(\mathrm{CCSDTQ} /(\mathrm{d})$-aug-cc-pVDZ) $]-E[(\mathrm{CCSD}(\mathrm{T}) /(\mathrm{d})$-aug-cc-pVDZ) $]$.

e: FPA estimate, using $E[C C S D T(P) /(d)$-aug-cc-pV $\infty \mathrm{Z}]=E[C C S D(T) /(d)$-aug-cc-pVoZ $]+$ $E[(\operatorname{CCSDTQ}(\mathrm{P}) /(\mathrm{d})$-aug-cc-pVDZ) $]-E[(\mathrm{CCSD}(\mathrm{T}) /(\mathrm{d})$-aug-cc-pVDZ) $]$ 
Table 9: Polarizability tensor $\left(\alpha_{\mathrm{xx}}=\alpha_{\mathrm{yy}}, \alpha_{\mathrm{zz}}\right)$ of HCN at the CCSD(T)/aug-cc-pVXZ levels and beyond (FPA results; all values are in a.u.)

\begin{tabular}{|c|c|c|}
\hline$\alpha_{\mathrm{xx}}$ & adiabatic & electronic \\
\hline $\mathrm{CCSD}(\mathrm{T}) / \mathrm{X}=\mathrm{Q}$ & 13.9242 & 13.8968 \\
\hline $\mathrm{CCSD}(\mathrm{T}) / \mathrm{X}=5$ & 13.8706 & 13.8701 \\
\hline $\mathrm{CCSD}(\mathrm{T}) / \mathrm{X}=6$ & 13.8626 & 13.8593 \\
\hline $\mathrm{CCSD}(\mathrm{T}) / \mathrm{X}=\infty^{\mathrm{a}}$ & 13.8656 & 13.8474 \\
\hline $\mathrm{CCSDT}^{\mathrm{b}} / \mathrm{X}=\infty^{\mathrm{a}}$ & & 13.8402 \\
\hline $\mathrm{CCSDT}(\mathrm{Q})^{\mathrm{c}} / \mathrm{X}=\infty^{\mathrm{a}}$ & & 13.8486 \\
\hline $\mathrm{CCSDTQ}^{\mathrm{d}} / \mathrm{X}=\infty^{\mathrm{a}}$ & & 13.8486 \\
\hline $\left.\mathrm{CCSDTQ}^{\mathrm{P}} \mathrm{P}\right)^{\mathrm{e}} / \mathrm{X}=\infty^{\mathrm{a}}$ & & $\mathbf{1 3 . 8 4 7 8}$ \\
\hline
\end{tabular}

\begin{tabular}{|c|c|c|}
\hline$\alpha_{\mathrm{zz}}$ & adiabatic & electronic \\
\hline $\mathrm{CCSD}(\mathrm{T}) / \mathrm{X}=\mathrm{Q}$ & 22.3881 & 22.1616 \\
\hline $\mathrm{CCSD}(\mathrm{T}) / \mathrm{X}=5$ & 22.2740 & 22.1245 \\
\hline $\mathrm{CCSD}(\mathrm{T}) / \mathrm{X}=6$ & 22.2799 & 22.1109 \\
\hline $\mathrm{CCSD}(\mathrm{T}) / \mathrm{X}=\infty^{\mathrm{a}}$ & 22.3355 & 22.0974 \\
\hline $\mathrm{CCSDT}^{\mathrm{b}} / \mathrm{X}=\infty^{\mathrm{a}}$ & & 22.1279 \\
\hline $\mathrm{CCSDT}(\mathrm{Q})^{\mathrm{c}} / \mathrm{X}=\infty^{\mathrm{a}}$ & & 22.1055 \\
\hline $\mathrm{CCSDTQ}^{\mathrm{d}} / \mathrm{X}=\infty^{\mathrm{a}}$ & & 22.1051 \\
\hline $\mathrm{CCSDTQ}^{\mathrm{P}}(\mathrm{P})^{\mathrm{e}} / \mathrm{X}=\infty^{\mathrm{a}}$ & & $\mathbf{2 2 . 1 0 0 6}$ \\
\hline
\end{tabular}
a: 3-point extrapolation employing $X=Q, 5,6$;
b: FPA estimate, using $E[C C S D T /$ aug-cc-pV $\infty \mathrm{Z}]=E[\mathrm{CCSD}(\mathrm{T}) /($ aug-cc-pV $\infty \mathrm{Z}]+E[(\mathrm{CCSDT} /$ (aug- cc-pVTZ) $]-E[(\mathrm{CCSD}(\mathrm{T}) /$ aug-cc-pVTZ) $]$.
c: FPA estimate, using $E[C C S D T(Q) /($ aug-cc-pV $\infty Z]=E[C C S D(T) /($ aug-cc-pVoZ $]+$ $E[(\operatorname{CCSDT}(\mathrm{Q}) /($ aug-cc-pVTZ) $]-E[(\mathrm{CCSD}(\mathrm{T}) /($ aug-cc-pVTZ) $]$.
$\mathrm{d}$ : FPA estimate, using $E[C C S D T Q /($ aug-cc-pVœZ $]=E[C C S D(T) /($ aug-cc-pV $\infty Z]+$ $E[(\mathrm{CCSDTQ} /($ aug-cc-pVDZ) $]-E[(\mathrm{CCSD}(\mathrm{T}) /($ aug-cc-pVDZ) $]$.
e: FPA estimate, using $E[C C S D T(P) /($ aug-cc-pVœZ $]=E[C C S D(T) /($ aug-cc-pV $\infty Z]+$ $E[(\mathrm{CCSDTQ}(\mathrm{P}) /$ aug-cc-pVDZ $)]-E[(\mathrm{CCSD}(\mathrm{T}) /$ aug-cc-pVDZ $)]$ 
Table 10: Polarizability tensor $\left(\alpha_{\mathrm{xx}}=\alpha_{\mathrm{yy}}, \alpha_{\mathrm{zz}}\right)$ and isotropic polarizability $(\bar{\alpha})$ of HCCH at the CCSD(T)/aug-cc-pVXZ level and beyond (FPA results; all values are in a.u.)

\begin{tabular}{|c|c|c|}
\hline$\alpha_{\mathrm{xx}}$ & adiabatic & electronic \\
\hline $\mathrm{CCSD}(\mathrm{T}) / \mathrm{X}=\mathrm{Q}$ & 18.6473 & 18.6167 \\
\hline $\mathrm{CCSD}(\mathrm{T}) / \mathrm{X}=5$ & 18.5910 & 18.5930 \\
\hline $\mathrm{CCSD}(\mathrm{T}) / \mathrm{X}=6$ & 18.6051 & 18.5942 \\
\hline $\mathrm{CCSD}(\mathrm{T}) / \mathrm{X}=\infty^{\mathrm{a}}$ & 18.6584 & 18.6100 \\
\hline $\mathrm{CCSDT}^{\mathrm{b}} / \mathrm{X}=\infty^{\mathrm{a}}$ & & 18.6039 \\
\hline $\mathrm{CCSDT}(\mathrm{Q})^{\mathrm{c}} / \mathrm{X}=\infty^{\mathrm{a}}$ & & 18.5931 \\
\hline $\mathrm{CCSDTQ}^{\mathrm{d}} / \mathrm{X}=\infty^{\mathrm{a}}$ & & 18.5968 \\
\hline $\mathrm{CCSDTQ}^{\mathrm{P}}(\mathrm{P})^{\mathrm{e}} / \mathrm{X}=\infty^{\mathrm{a}}$ & & $\mathbf{1 8 . 5 9 3 6}$ \\
\hline
\end{tabular}

\begin{tabular}{|c|c|c|}
\hline$\alpha_{\mathrm{zz}}$ & adiabatic & electronic \\
\hline $\mathrm{CCSD}(\mathrm{T}) / \mathrm{X}=\mathrm{Q}$ & 30.5701 & 30.2771 \\
\hline $\mathrm{CCSD}(\mathrm{T}) / \mathrm{X}=5$ & 30.4241 & 30.2364 \\
\hline $\mathrm{CCSD}(\mathrm{T}) / \mathrm{X}=6$ & 30.4753 & 30.2403 \\
\hline $\mathrm{CCSD}(\mathrm{T}) / \mathrm{X}=\infty^{\mathrm{a}}$ & 30.6327 & 30.2563 \\
\hline $\mathrm{CCSDT}^{\mathrm{b}} / \mathrm{X}=\infty^{\mathrm{a}}$ & & 30.2993 \\
\hline $\mathrm{CCSDT}(\mathrm{Q})^{\mathrm{c}} / \mathrm{X}=\infty^{\mathrm{a}}$ & & 30.2484 \\
\hline $\mathrm{CCSDTQ}^{\mathrm{d}} / \mathrm{X}=\infty^{\mathrm{a}}$ & & 30.2496 \\
\hline $\mathrm{CCSDTQ}^{\mathrm{P}}(\mathrm{P})^{\mathrm{e}} / \mathrm{X}=\infty^{\mathrm{a}}$ & & $\mathbf{3 0 . 2 3 9 3}$ \\
\hline
\end{tabular}

\begin{tabular}{|c|c|c|}
\hline $\bar{\alpha}$ & adiabatic & electronic \\
\hline $\mathrm{CCSD}(\mathrm{T}) / \mathrm{X}=\mathrm{Q}$ & 22.6216 & 22.5035 \\
\hline $\mathrm{CCSD}(\mathrm{T}) / \mathrm{X}=5$ & 22.5354 & 22.4742 \\
\hline $\mathrm{CCSD}(\mathrm{T}) / \mathrm{X}=6$ & 22.5618 & 22.4762 \\
\hline $\mathrm{CCSD}(\mathrm{T}) / \mathrm{X}=\infty^{\mathrm{a}}$ & 22.6498 & 22.4906 \\
\hline $\mathrm{CCSDT}^{\mathrm{b}} / \mathrm{X}=\infty^{\mathrm{a}}$ & & 22.5024 \\
\hline $\mathrm{CCSDT}(\mathrm{Q})^{\mathrm{c}} / \mathrm{X}=\infty^{\mathrm{a}}$ & & 22.4782 \\
\hline $\mathrm{CCSDTQ}^{\mathrm{d}} / \mathrm{X}=\infty^{\mathrm{a}}$ & & 22.4811 \\
\hline $\mathrm{CCSDTQ}(\mathrm{P})^{\mathrm{e}} / \mathrm{X}=\infty^{\mathrm{a}}$ & & $\mathbf{2 2 . 4 7 5 5}$ \\
\hline
\end{tabular}

a: 3-point extrapolation employing $X=Q, 5,6$;

b: FPA estimate, using $E[C C S D T /$ aug-cc-pV $\infty Z]=E[C C S D(T) /$ aug-cc-pV $\infty Z]+E[(C C S D T / a u g-c c-$ pVTZ) $]-E[(\operatorname{CCSD}(\mathrm{T}) /($ aug-cc-pVTZ) .

c: FPA estimate, using $E[C C S D T(Q) / a u g-c c-p V \infty Z]=E[C C S D(T) /($ aug-cc-pVœZ $]+$ $E[(\operatorname{CCSDT}(\mathrm{Q}) /$ aug-cc-pVTZ) $]-E[(\mathrm{CCSD}(\mathrm{T}) /$ aug-cc-pVTZ) $]$.

$\mathrm{d}$ : FPA estimate, using $E[C C S D T Q / a u g-c c-p V \infty Z]=E[C C S D(T) / a u g-c c-p V \infty Z]+$ $E[(\mathrm{CCSDTQ} /$ aug-cc-pVDZ) $]-E[(\mathrm{CCSD}(\mathrm{T}) / \mathrm{aug}-\mathrm{cc}-\mathrm{pVDZ})]$. 
e: FPA estimate, using $E[C C S D T(P) /(d)$-aug-cc-pVœZ $]=E[C C S D(T) /(d)-a u g-c c-p V \infty Z]+$ $E[(\mathrm{CCSDTQ}(\mathrm{P}) /(\mathrm{d})$-aug-cc-pVDZ) $]-E[(\mathrm{CCSD}(\mathrm{T}) /(\mathrm{d})$-aug-cc-pVDZ) $]$ 
Table 11: Polarizability tensor $\left(\alpha_{\mathrm{xx}}, \alpha_{\mathrm{yy}}, \alpha_{\mathrm{zz}}\right)$ and isotropic polarizability $(\bar{\alpha})$ of $\mathrm{C}_{2} \mathrm{H}_{4}$ at the CCSD(T) level and beyond (FPA results; all values are in a.u.)

\begin{tabular}{|c|c|c|}
\hline$\alpha_{\mathrm{xx}}$ & adiabatic & electronic \\
\hline $\mathrm{CCSD}(\mathrm{T}) / \mathrm{X}=\mathrm{Q}$ & 24.3243 & 21.7471 \\
\hline $\mathrm{CCSD}(\mathrm{T}) / \mathrm{X}=5$ & 24.2920 & 21.7040 \\
\hline $\mathrm{CCSD}(\mathrm{T}) / \mathrm{X}=6$ & 24.2482 & 21.6793 \\
\hline $\left.\mathrm{CCSD}^{\mathrm{T}}\right) / \mathrm{X}=\infty^{\mathrm{a}}$ & 24.1796 & 21.6531 \\
\hline $\mathrm{CCSDT}^{\mathrm{b}} / \mathrm{X}=\infty^{\mathrm{a}}$ & & 21.6476 \\
\hline $\mathrm{CCSDT}^{\mathrm{a}}(\mathrm{Q})^{\mathrm{c}} / \mathrm{X}=\infty^{\mathrm{a}}$ & & 21.6417 \\
\hline $\mathrm{CCSDTQ}^{\mathrm{d}} / \mathrm{X}=\infty^{\mathrm{a}}$ & & $\mathbf{2 1 . 6 4 5 5}$ \\
\hline
\end{tabular}

\begin{tabular}{|c|c|c|}
\hline$\alpha_{\mathrm{yy}}$ & adiabatic & electronic \\
\hline $\mathrm{CCSD}(\mathrm{T}) / \mathrm{X}=\mathrm{Q}$ & 24.7594 & 24.5897 \\
\hline $\mathrm{CCSD}(\mathrm{T}) / \mathrm{X}=5$ & 24.6405 & 24.5980 \\
\hline $\mathrm{CCSD}(\mathrm{T}) / \mathrm{X}=6$ & 24.7031 & 24.5949 \\
\hline $\mathrm{CCSD}(\mathrm{T}) / \mathrm{X}=\infty^{\mathrm{a}}$ & 24.8703 & 24.5742 \\
\hline $\mathrm{CCSDT}^{\mathrm{b}} / \mathrm{X}=\infty^{\mathrm{a}}$ & & 24.5729 \\
\hline $\left.\mathrm{CCSDT}^{\mathrm{a}} \mathrm{Q}\right)^{\mathrm{c}} / \mathrm{X}=\infty^{\mathrm{a}}$ & & 24.5898 \\
\hline $\mathrm{CCSDTQ}^{\mathrm{d}} / \mathrm{X}=\infty^{\mathrm{a}}$ & & $\mathbf{2 4 . 5 8 9 2}$ \\
\hline
\end{tabular}

\begin{tabular}{|c|c|c|}
\hline$\alpha_{\mathrm{zz}}$ & adiabatic & electronic \\
\hline $\mathrm{CCSD}(\mathrm{T}) / \mathrm{X}=\mathrm{Q}$ & 34.0078 & 33.7563 \\
\hline $\mathrm{CCSD}(\mathrm{T}) / \mathrm{X}=5$ & 33.8718 & 33.7271 \\
\hline $\mathrm{CCSD}(\mathrm{T}) / \mathrm{X}=6$ & 33.8832 & 33.7191 \\
\hline $\mathrm{CCSD}(\mathrm{T}) / \mathrm{X}=\infty^{\mathrm{a}}$ & 33.9565 & 33.7087 \\
\hline $\mathrm{CCSDT}^{\mathrm{b}} / \mathrm{X}=\infty^{\mathrm{a}}$ & & 33.7544 \\
\hline $\left.\mathrm{CCSDT}^{\mathrm{a}} \mathrm{Q}\right)^{\mathrm{c}} / \mathrm{X}=\infty^{\mathrm{a}}$ & & 33.7142 \\
\hline $\mathrm{CCSDTQ}^{\mathrm{d}} / \mathrm{X}=\infty^{\mathrm{a}}$ & & $\mathbf{3 3 . 7 1 6 7}$ \\
\hline
\end{tabular}

\begin{tabular}{|c|c|c|}
\hline $\bar{\alpha}$ & adiabatic & electronic \\
\hline $\mathrm{CCSD}(\mathrm{T}) / \mathrm{X}=\mathrm{Q}$ & 27.6972 & 26.6977 \\
\hline $\mathrm{CCSD}(\mathrm{T}) / \mathrm{X}=5$ & 27.6014 & 26.6764 \\
\hline $\mathrm{CCSD}(\mathrm{T}) / \mathrm{X}=6$ & 27.6115 & 26.6644 \\
\hline $\mathrm{CCSD}(\mathrm{T}) / \mathrm{X}=\infty^{\mathrm{a}}$ & 27.6688 & 26.6453 \\
\hline $\mathrm{CCSDT}^{\mathrm{b}} / \mathrm{X}=\infty^{\mathrm{a}}$ & & 26.6583 \\
\hline $\mathrm{CCSDT}^{\mathrm{a}}(\mathrm{Q})^{\mathrm{c}} / \mathrm{X}=\infty^{\mathrm{a}}$ & & 26.6486 \\
\hline $\mathrm{CCSDTQ}^{\mathrm{d}} / \mathrm{X}=\infty^{\mathrm{a}}$ & & $\mathbf{2 6 . 6 5 0 5}$ \\
\hline \multicolumn{2}{|l}{}
\end{tabular}

a: 3-point extrapolation employing $X=Q, 5,6$;

b: FPA estimate, using $E[C C S D T / a u g-c c-p V \infty Z]=E[C C S D(T) / a u g-c c-p V \infty Z]+E[(C C S D T / a u g-c c-p V T Z)]-$ $E[(\operatorname{CCSD}(\mathrm{T}) /($ aug-cc-pVTZ) $]$.

c: FPA estimate, using $E[C C S D T(Q) /$ aug-cc-pV $\infty Z]=E[C C S D(T) /($ aug-cc-pV $\infty Z]+E[(\operatorname{CCSDT}(\mathrm{Q}) /($ aug-cc$\mathrm{pVTZ})]-E[(\mathrm{CCSD}(\mathrm{T}) /($ aug-cc-pVTZ) $]$.

$\mathrm{d}$ : FPA estimate, using $E[\mathrm{CCSDTQ} /$ aug-cc-pV $\infty \mathrm{Z}]=E[\mathrm{CCSD}(\mathrm{T}) /($ aug-cc-pV $\infty \mathrm{Z}]+E[(\mathrm{CCSDTQ} /$ aug-cc- 
pVDZ) $]-E[(C C S D(T) / a u g-c c-p V D Z)]$.

e: FPA estimate, using $E[C C S D T(P) /(d)$-aug-cc-pV $\infty \mathrm{Z}]=E[\operatorname{CCSD}(\mathrm{T}) /(\mathrm{d})$-aug-cc-pV $\infty \mathrm{Z}]+$ $E[(\mathrm{CCSDTQ}(\mathrm{P}) /($ aug-cc-pVDZ $)]-E[(\mathrm{CCSD}(\mathrm{T}) /($ aug-cc-pVDZ $)]$ 
Table 12: Polarizability tensor $\left(\alpha_{\mathrm{xx}}, \alpha_{\mathrm{yy}}, \alpha_{\mathrm{zz}}\right)$ and isotropic polarizability $(\bar{\alpha})$ of $\mathrm{C}_{2} \mathrm{H}_{6}$ $(\mathrm{CCSD}(\mathrm{T}) / \mathrm{aug}-\mathrm{cc}-\mathrm{pVXZ}$ results; all values are in a.u.)

\begin{tabular}{|c|c|c|}
\hline$\alpha_{\mathrm{xx}}$ & adiabatic & electronic \\
\hline $\mathrm{CCSD}(\mathrm{T}) / \mathrm{X}=\mathrm{T}$ & 26.8834 & 26.7436 \\
\hline $\mathrm{CCSD}(\mathrm{T}) / \mathrm{X}=\mathrm{Q}$ & 27.0664 & 26.6922 \\
\hline $\mathrm{CCSD}(\mathrm{T}) / \mathrm{X}=5$ & 27.3082 & 26.6744 \\
\hline $\mathrm{CCSD}(\mathrm{T}) / \mathrm{X}=\infty^{\mathrm{a}}$ & 27.6162 & 26.6586 \\
\hline $\mathrm{CCSDT}^{\mathrm{b}} / \mathrm{X}=\infty^{\mathrm{a}}$ & & 26.6693 \\
\hline $\left.\mathrm{CCSDT}^{\mathrm{Q}} \mathrm{Q}\right)^{\mathrm{c}} / \mathrm{X}=\infty^{\mathrm{a}}$ & & $\mathbf{2 6 . 6 8 0 1}$ \\
\hline
\end{tabular}

\begin{tabular}{|c|c|c|}
\hline$\alpha_{\mathrm{yy}}$ & adiabatic & electronic \\
\hline $\mathrm{CCSD}(\mathrm{T}) / \mathrm{X}=\mathrm{T}$ & 26.8868 & 26.7436 \\
\hline $\mathrm{CCSD}(\mathrm{T}) / \mathrm{X}=\mathrm{Q}$ & 27.0636 & 26.6922 \\
\hline $\mathrm{CCSD}(\mathrm{T}) / \mathrm{X}=5$ & 27.3002 & 26.6744 \\
\hline $\mathrm{CCSD}(\mathrm{T}) / \mathrm{X}=\infty^{\mathrm{a}}$ & 27.6022 & 26.6585 \\
\hline $\mathrm{CCSDT}^{\mathrm{b}} / \mathrm{X}=\infty^{\mathrm{a}}$ & & 26.6691 \\
\hline $\left.\mathrm{CCSDT}^{\mathrm{a}} \mathrm{Q}\right)^{\mathrm{c}} / \mathrm{X}=\infty^{\mathrm{a}}$ & & $\mathbf{2 6 . 6 8 0 0}$ \\
\hline
\end{tabular}

\begin{tabular}{|c|c|c|}
\hline$\alpha_{\mathrm{zz}}$ & adiabatic & electronic \\
\hline $\mathrm{CCSD}(\mathrm{T}) / \mathrm{X}=\mathrm{T}$ & 30.6695 & 30.5032 \\
\hline $\mathrm{CCSD}(\mathrm{T}) / \mathrm{X}=\mathrm{Q}$ & 30.6121 & 30.4456 \\
\hline $\mathrm{CCSD}(\mathrm{T}) / \mathrm{X}=5$ & 30.6050 & 30.4173 \\
\hline $\mathrm{CCSD}(\mathrm{T}) / \mathrm{X}=\infty^{\mathrm{a}}$ & 30.6097 & 30.3902 \\
\hline $\mathrm{CCSDT}^{\mathrm{b}} / \mathrm{X}=\infty^{\mathrm{a}}$ & & 30.3994 \\
\hline $\left.\mathrm{CCSDT}^{\mathrm{Q}} \mathrm{Q}\right)^{\mathrm{c}} / \mathrm{X}=\infty^{\mathrm{a}}$ & & $\mathbf{3 0 . 4 1 6 5}$ \\
\hline
\end{tabular}

\begin{tabular}{|c|c|c|}
\hline $\bar{\alpha}$ & adiabatic & electronic \\
\hline $\mathrm{CCSD}(\mathrm{T}) / \mathrm{X}=\mathrm{T}$ & 28.1465 & 27.9968 \\
\hline $\mathrm{CCSD}(\mathrm{T}) / \mathrm{X}=\mathrm{Q}$ & 28.2474 & 27.9433 \\
\hline $\mathrm{CCSD}(\mathrm{T}) / \mathrm{X}=5$ & 28.4045 & 27.9220 \\
\hline $\mathrm{CCSD}(\mathrm{T}) / \mathrm{X}=\infty^{\mathrm{a}}$ & 28.6093 & 27.9024 \\
\hline $\mathrm{CCSDT}^{\mathrm{b}} / \mathrm{X}=\infty^{\mathrm{a}}$ & & 27.9126 \\
\hline $\left.\mathrm{CCSDT}^{\mathrm{Q}} \mathrm{Q}\right)^{\mathrm{c}} / \mathrm{X}=\infty^{\mathrm{a}}$ & & $\mathbf{2 7 . 9 2 5 6}$ \\
\hline
\end{tabular}

a: 3-point extrapolation employing $\mathrm{X}=\mathrm{T}, \mathrm{Q}, 5$

b: FPA estimate, using $E[C C S D T / a u g-c c-p V \infty Z]=E[C C S D(T) / a u g-c c-p V \infty Z]+E[(C C S D T / a u g-c c-$ $\mathrm{pVDZ})]-E[(\mathrm{CCSD}(\mathrm{T}) /($ aug-cc-pVDZ) $]$.

c: FPA estimate, using $E[C C S D T(Q) / a u g-c c-p V \infty Z]=E[C C S D(T) /($ aug-cc-pV $\infty Z]+$ $E[(\mathrm{CCSDT}(\mathrm{Q}) /($ aug-cc-pVDZ) $]-E[(\mathrm{CCSD}(\mathrm{T}) /($ aug-cc-pVDZ) $]$. 
Table 13: Comparison of Born-Oppenheimer Molecular Dynamical Estimates of thermally averaged electronic isotropic polarizabilities $(\langle\bar{\alpha}\rangle)$ with equilibrium $\left(\bar{\alpha}_{e}\right)$ and experimental values (all results are in a.u.)

\begin{tabular}{|c|c|c|c|c|c|c|c|c|}
\hline & $\begin{array}{c}\bar{\alpha}_{e} \\
\text { (FPA } \\
\text { result) }\end{array}$ & $\begin{array}{c}\bar{\alpha}_{e} \\
\left(\omega \mathrm{B} 97 \mathrm{XD}^{\mathrm{a}}\right)\end{array}$ & $\begin{array}{c}\Delta \mathrm{t} \\
(\mathrm{fs})^{\mathrm{c}}\end{array}$ & $\langle\bar{\alpha}\rangle_{B O M D}{ }^{\mathrm{d}}$ & $\begin{array}{c}\langle\bar{\alpha}\rangle_{\text {BOMD }}-\bar{\alpha}_{e} \\
(\omega \mathrm{B} 97 \mathrm{XD})\end{array}$ & $\langle\bar{\alpha}\rangle_{Z P V}-\bar{\alpha}_{e}$ & $\langle\bar{\alpha}\rangle_{F P A}{ }^{\mathrm{h}}$ & Exp \\
\hline $\mathrm{CO}$ & 13.00 & 13.13 & 5862 & 13.16 & 0.03 & $0.05^{f}$ & 13.03 & $13.09^{1}$ \\
\hline $\mathrm{N}_{2}$ & 11.67 & 11.85 & 5835 & 11.88 & 0.03 & $0.05^{\mathrm{f}}$ & 11.70 & $11.74^{j}$ \\
\hline $\mathrm{F}_{2}$ & 8.32 & 8.16 & 7051 & 8.20 & 0.04 & - & 8.36 & $8.27^{\mathrm{k}}$ \\
\hline $\mathrm{HF}$ & 5.53 & 5.55 & 1962 & 5.62 & 0.07 & $0.10^{\mathrm{f}}$ & 5.60 & $5.60^{1}$ \\
\hline $\mathrm{H}_{2} \mathrm{O}$ & 9.50 & 9.65 & 3441 & 9.87 & 0.22 & $0.31^{\mathrm{g}}$ & 9.72 & $\begin{array}{l}9.47^{\mathrm{m}} \\
9.92^{\mathrm{n}}\end{array}$ \\
\hline $\mathrm{HCN}$ & 16.60 & 16.97 & 4020 & 17.18 & 0.21 & - & 16.81 & $\begin{array}{l}16.09^{\circ} \\
16.74^{\mathrm{p}}\end{array}$ \\
\hline $\mathrm{C}_{2} \mathrm{H}_{2}$ & 22.48 & 23.32 & 2079 & 23.82 & 0.50 & - & 22.98 & $22.96^{q}$ \\
\hline $\mathrm{C}_{2} \mathrm{H}_{4}$ & 26.65 & 27.71 & 1718 & 28.63 & 0.92 & - & 27.57 & $\begin{array}{l}27.70^{\mathrm{r}} \\
27.82^{\mathrm{s}}\end{array}$ \\
\hline $\mathrm{C}_{2} \mathrm{H}_{6}$ & 27.93 & $29.04^{b}$ & 3361 & $30.54^{\mathrm{e}}$ & 1.50 & - & 29.43 & - \\
\hline
\end{tabular}

a: Results obtained using the aug-cc-pVTZ basis set.

b: Results obtained using the aug-cc-pVDZ basis set.

c: run time of BOMD simulations.

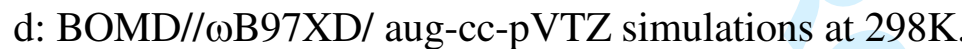

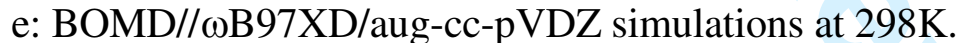

f: $\operatorname{CCSD}(\mathrm{T}) /$ aug-cc-pVQZ zero-point vibrational corrections to $\bar{\alpha}$ by O. Christiansen et al in ref. 62 (according to an average of the polarizability tensor by means of a spline integration over the lowest vibrational quantized state).

g: CCSD/aug-cc-pVœZ zero-point vibrational corrections to $\bar{\alpha}$ by G. Avila in ref. 56 (according to an average of the polarizability tensor by means of a Gauss-Hermite quadrature over the lowest vibrational quantized state).

h: final estimate of vibrationally averaged isotropic values of electronic static dipole polarizabilities, based on the FPA values for $\bar{\alpha}_{e}$ and BOMD// $\omega \mathrm{B} 97 \mathrm{XD}$ results for the vibrational correction, i.e. $\langle\bar{\alpha}\rangle_{B O M D}-\bar{\alpha}_{e}$.

i: Reference 51.

j: Reference 51 .

$\mathrm{k}$ : Reference 52.

1: value extrapolated from refractive index in ref. 10a.

m: Reference 47.

$\mathrm{n}$ : Dynamic value (514.5 nm) by Murphy [63].

o: Reference 59.

p: Reference 64.

q: Reference 59.

r: Reference 51.

s. Reference 65. 
Table 14: Comparison of static dipole electronic polarizabilities obtained in the HF/(d)aug/ccPV $\infty \mathrm{Z}$ limits using Karton-Martin modification of Jensen's formula versus results obtained using the original Feller's formula.

\begin{tabular}{|c|c|c|c|c|c|}
\hline & $\begin{array}{l}\text { Largest basis set } \\
\text { used in the } \\
\text { extrapolation }\end{array}$ & $\begin{array}{l}\text { Karton-Martin's } \\
\text { extrapolation }\end{array}$ & $\begin{array}{l}\text { Feller's } \\
\text { extropolation }\end{array}$ & $\begin{array}{l}\text { Polarizability } \\
\text { Difference }^{\mathrm{a}}\end{array}$ & $\begin{array}{l}\text { Extrapolated } \\
\text { energy } \\
\text { difference }^{b}\end{array}$ \\
\hline $\mathrm{Ne}$ & aug-cc-pV6Z & 2.3708 & 2.3712 & 0.0003 & 29226.7 \\
\hline $\mathrm{Ne}$ & d-aug-cc-pV6Z & 2.3763 & 2.3763 & 0.0000 & 29150.4 \\
\hline \multirow[t]{2}{*}{$\mathrm{N}_{2}\left(\alpha_{\mathrm{xx}}\right)$} & aug-cc-pV6Z & 9.8243 & 9.8243 & 0.0001 & 11031.4 \\
\hline & d-aug-cc-pV6Z & 9.8232 & 9.8232 & 0.0000 & 11183.6 \\
\hline \multirow[t]{2}{*}{$\mathrm{N}_{2}\left(\alpha_{\mathrm{zz}}\right)$} & aug-cc-pV6Z & 15.0073 & 15.0075 & 0.0002 & \\
\hline & d-aug-cc-pV6Z & 15.0042 & 15.0043 & 0.0001 & \\
\hline \multirow[t]{2}{*}{$\mathrm{F}_{2}\left(\alpha_{\mathrm{xx}}\right)$} & aug-cc-pV6Z & 5.5524 & 5.5524 & 0.0000 & 38530.9 \\
\hline & d-aug-cc-pV6Z & 5.5563 & 5.5563 & 0.0000 & 36584.1 \\
\hline \multirow[t]{2}{*}{$\mathrm{F}_{2}\left(\alpha_{\mathrm{zz}}\right)$} & aug-cc-pV6Z & 14.5361 & 14.5359 & 0.0002 & \\
\hline & d-aug-cc-pV6Z & 14.5280 & 14.5281 & 0.0001 & \\
\hline \multirow[t]{2}{*}{$\operatorname{CO}\left(\alpha_{x x}\right)$} & aug-cc-pV6Z & 11.2674 & 11.2676 & 0.0001 & 13949.7 \\
\hline & d-aug-cc-pV6Z & 11.2677 & 11.2677 & 0.0000 & 13487.5 \\
\hline \multirow[t]{2}{*}{$\operatorname{CO}\left(\alpha_{\mathrm{zz}}\right)$} & aug-cc-pV6Z & $\begin{array}{r}4.4505 \\
\end{array}$ & 14.4506 & 0.0001 & \\
\hline & d-aug-cc-pV6Z & 14.4486 & 14.4486 & 0.0000 & \\
\hline \multirow[t]{2}{*}{$\operatorname{HF}\left(\alpha_{x x}\right)$} & aug-cc-pV6Z & 4.4479 & 4.4778 & 0.0001 & 19246.5 \\
\hline & d-aug-cc-pV6Z & 4.4861 & 4.4862 & 0.0000 & 18964.5 \\
\hline \multirow[t]{2}{*}{$\mathrm{HF}\left(\alpha_{\mathrm{zz}}\right)$} & aug-cc-pV6Z & 5.7451 & 5.7451 & 0.0000 & \\
\hline & d-aug-cc-pV6Z & 5.7461 & 5.7461 & 0.0000 & \\
\hline $\mathrm{C}_{2} \mathrm{H}_{2}\left(\alpha_{\mathrm{xx}}\right)$ & aug-cc-pV6Z & 19.3535 & 19.3535 & 0.0001 & 6940.9 \\
\hline $\mathrm{C}_{2} \mathrm{H}_{2}\left(\alpha_{z \mathrm{z}}\right)$ & aug-cc-pV6Z & 31.3553 & 31.3559 & 0.0006 & \\
\hline $\operatorname{HCN}\left(\alpha_{x x}\right)$ & aug-cc-pV6Z & 13.8721 & 13.8721 & 0.0000 & 8815.5 \\
\hline $\operatorname{HCN}\left(\alpha_{z z}\right)$ & aug-cc-pV6Z & 22.4123 & 22.4124 & 0.0000 & \\
\hline \multirow[t]{2}{*}{$\mathrm{H}_{2} \mathrm{O}\left(\alpha_{\mathrm{xx}}\right)$} & aug-cc-pV6Z & 7.8914 & 7.8915 & 0.0001 & 12156.2 \\
\hline & d-aug-cc-pV6Z & 7.8975 & 7.8975 & 0.0000 & 12079.2 \\
\hline \multirow[t]{2}{*}{$\mathrm{H}_{2} \mathrm{O}\left(\alpha_{\mathrm{yy}}\right)$} & aug-cc-pV6Z & 9.1718 & 9.1719 & 0.0001 & \\
\hline & d-aug-cc-pV6Z & 9.1742 & 9.1742 & 0.0000 & \\
\hline \multirow[t]{2}{*}{$\mathrm{H}_{2} \mathrm{O}\left(\alpha_{\mathrm{zz}}\right)$} & aug-cc-pV6Z & 8.5104 & 8.5104 & 0.0000 & \\
\hline & d-aug-cc-pV6Z & 8.5173 & 8.5173 & 0.0000 & \\
\hline $\mathrm{C}_{2} \mathrm{H}_{4}\left(\alpha_{\mathrm{xx}}\right)$ & aug-cc-pV6Z & 22.7491 & 22.7485 & 0.0005 & 7745.7 \\
\hline $\mathrm{C}_{2} \mathrm{H}_{4}\left(\alpha_{\mathrm{yy}}\right)$ & aug-cc-pV6Z & 24.4088 & 22.4097 & 0.0009 & \\
\hline $\mathrm{C}_{2} \mathrm{H}_{4}\left(\alpha_{\mathrm{zz}}\right)$ & aug-cc-pV6Z & 36.3603 & 36.3606 & 0.0004 & \\
\hline $\mathrm{C}_{2} \mathrm{H}_{6}\left(\alpha_{\mathrm{xx}}\right)$ & aug-cc-pV5Z & 26.1518 & 26.1522 & 0.0004 & -209736.5 \\
\hline $\mathrm{C}_{2} \mathrm{H}_{6}\left(\alpha_{\mathrm{zz}}\right)$ & aug-cc-pV5Z & 29.4553 & 29.4529 & 0.0024 & \\
\hline
\end{tabular}

a: in atomic units

b: $\mathrm{E}^{\mathrm{HF}} / \mathrm{CBS}\left[\right.$ Feller] - $\mathrm{E}^{\mathrm{HF}} / \mathrm{CBS}[$ Karton-Martin] at zero field; values provided in $n \mathrm{H}$. 


\section{Figure Captions.}

Figure 1. Evolution of the static polarizability of Neon as a function of the theoretical level attained in the treatment of electron correlation: (a) cc-pVXZ results; (b) aug-cc-pVXZ results; (c) daug-cc-pVXZ results.

Figure 2. Evolution of the (purely electronic, i.e. unrelaxed) static polarizability tensor of Carbon Monoxide ( $\mathrm{CO}$ ) as a function of the theoretical level attained in the treatment of electron correlation (results obtained using the d-aug-cc-pVXZ basis sets): (a) $\alpha_{x x}=\alpha_{y y}$; (b) $\alpha_{z z}$.

Figure 3. Evolution of the (purely electronic, i.e. unrelaxed) static polarizability tensor of the Nitrogen molecule $\left(\mathrm{N}_{2}\right)$ as a function of the theoretical level attained in the treatment of electron correlation (results obtained using the d-aug-cc-pVXZ basis sets): (a) $\alpha_{x x}=\alpha_{y y}$; (b) $\alpha_{z z}$.

Figure 4. Evolution of the (purely electronic, i.e. unrelaxed) static polarizability tensor of water $\left(\mathrm{H}_{2} \mathrm{O}\right)$ as a function of the theoretical level attained in the treatment of electron correlation (results obtained using the d-aug-cc-pVXZ basis sets): (a) $\alpha_{x x}$; (b) $\alpha_{y y}$; (c) $\alpha_{z z}$.

Figure 5. Evolution of the (purely electronic, i.e. unrelaxed) static polarizability tensor of acetylene $\left(\mathrm{C}_{2} \mathrm{H}_{2}\right)$ as a function of the theoretical level attained in the treatment of electron correlation (results obtained using the d-aug-cc-pVXZ basis sets): (a) $\alpha_{x x}=\alpha_{y y}$; (b) $\alpha_{z z}$.

Figure 6. Evolution of the (purely electronic, i.e. unrelaxed) static polarizability tensor of ethylene $\left(\mathrm{C}_{2} \mathrm{H}_{6}\right)$ as a function of the theoretical level attained in the treatment of electron correlation (results obtained using the d-aug-cc-pVXZ basis sets): (a) $\alpha_{x x}=\alpha_{y y}$; (b) $\alpha_{z z}$. 
Ne Polarizability

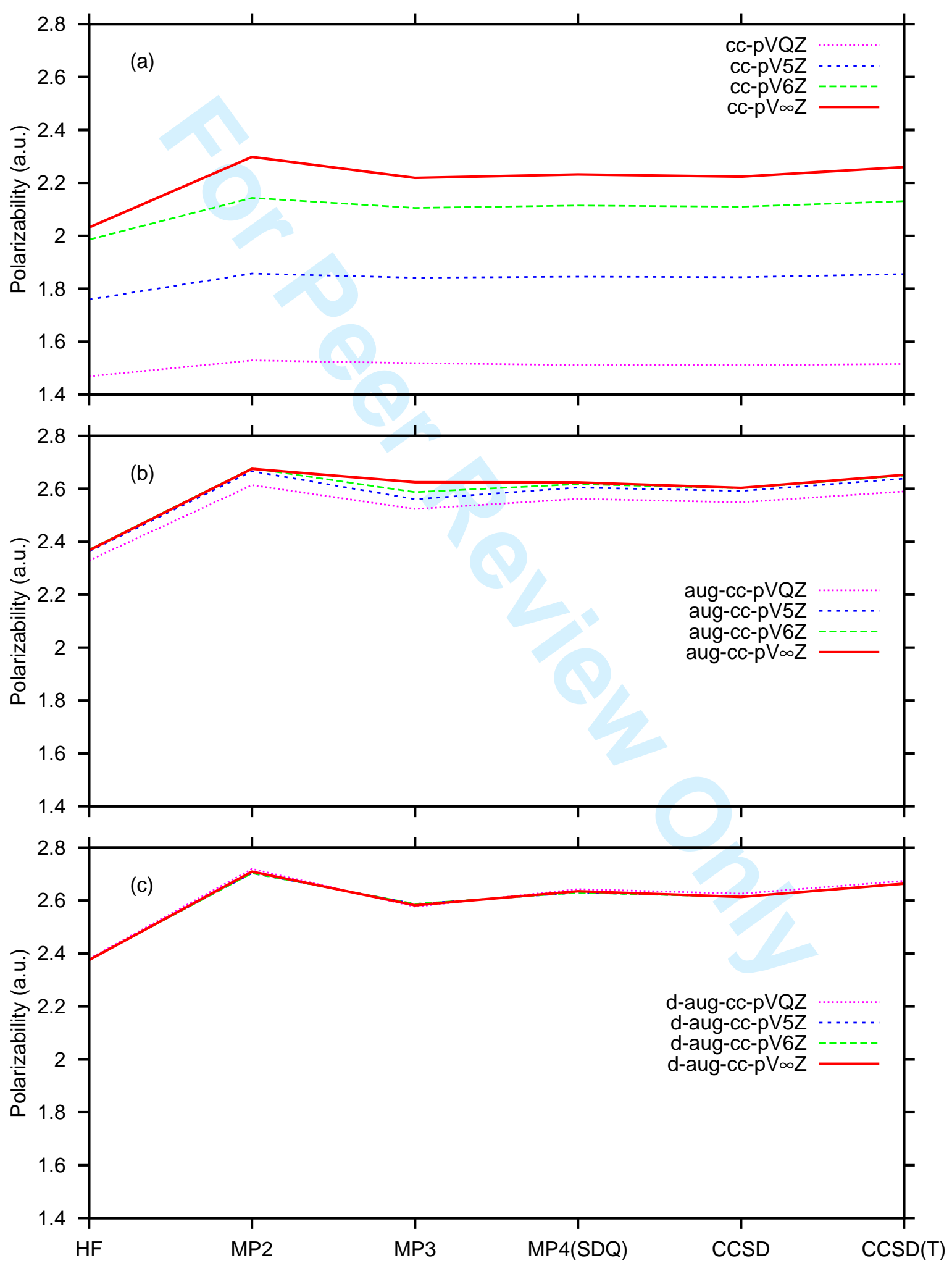




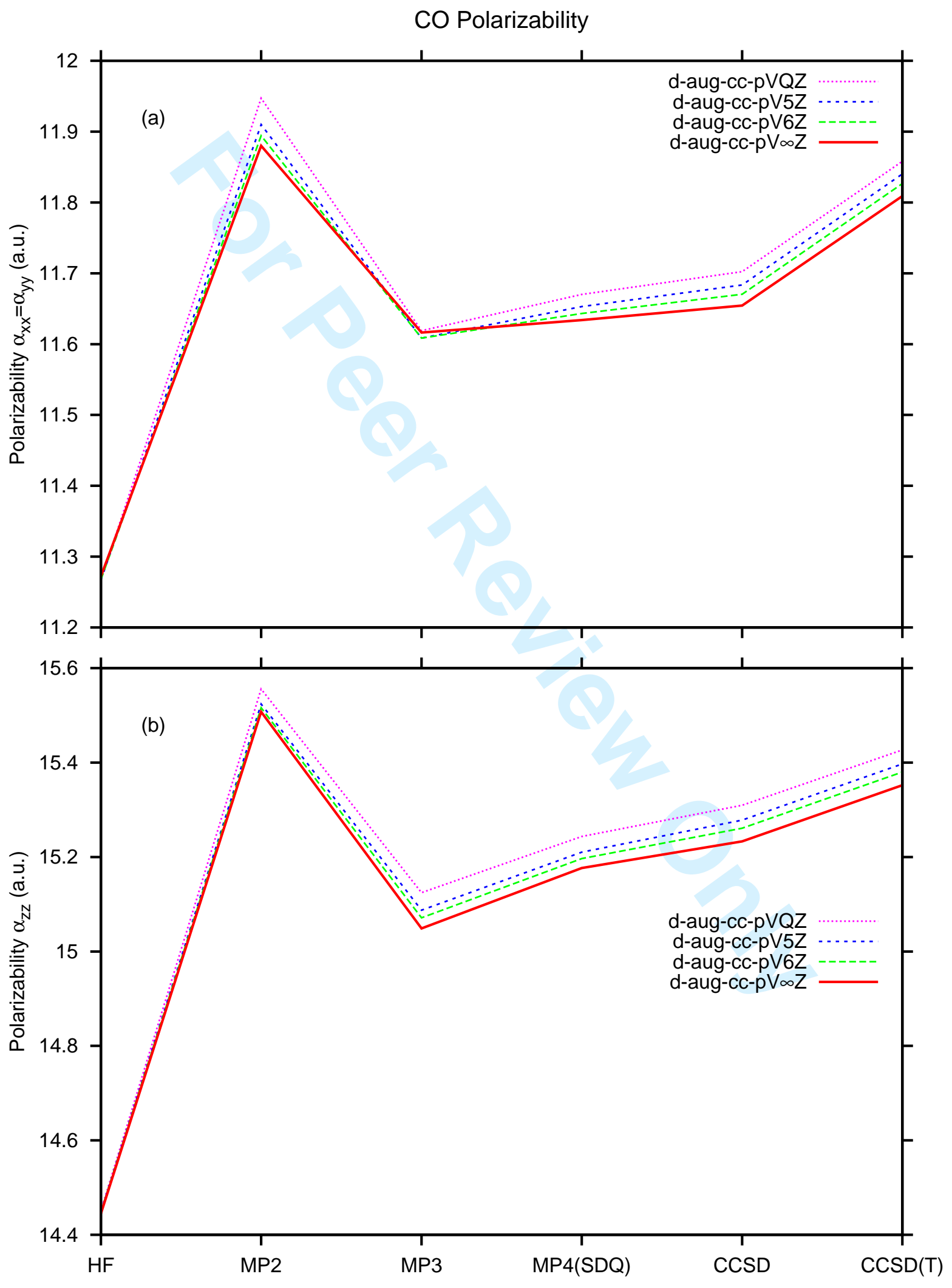




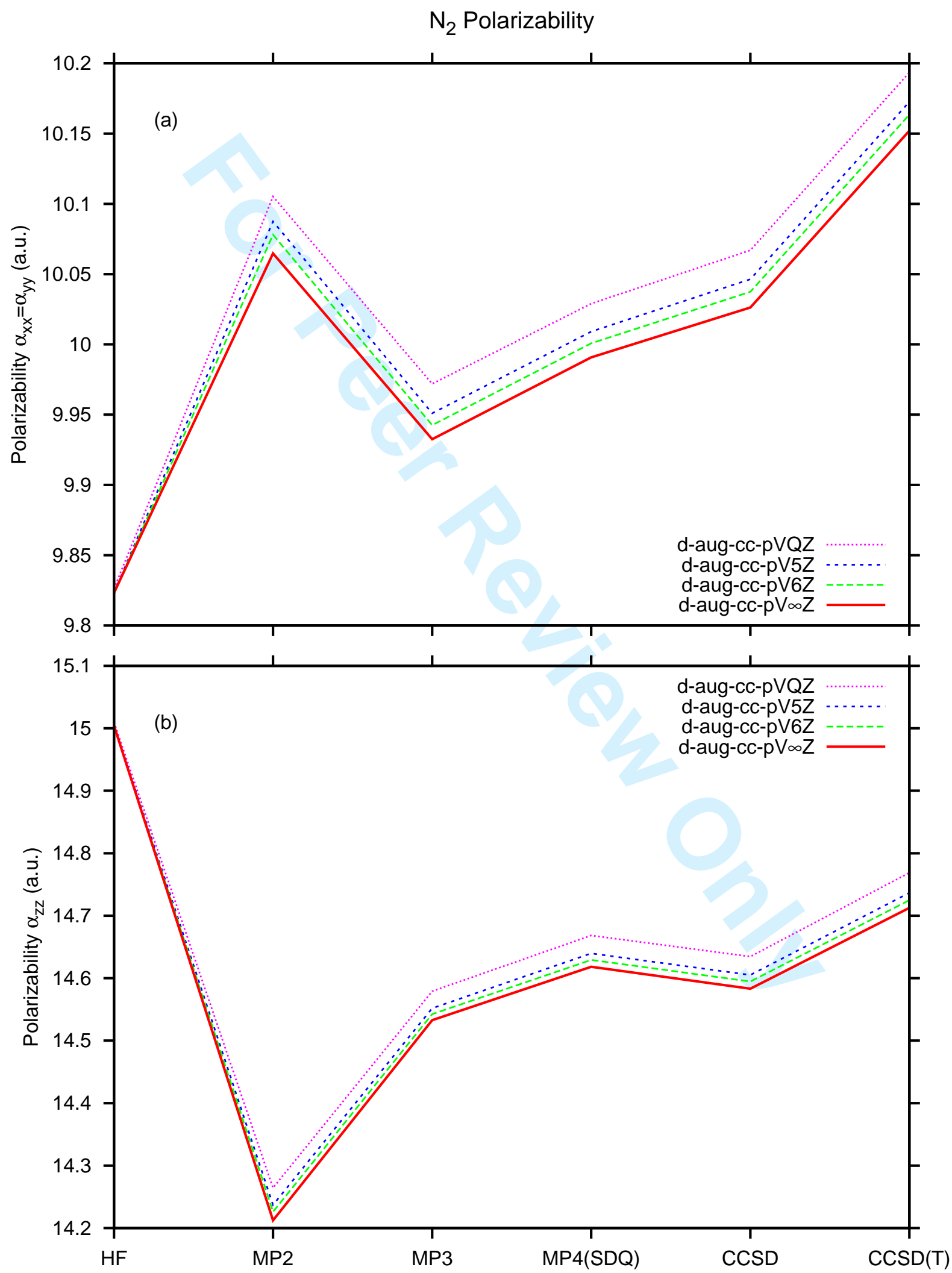


$\mathrm{H}_{2} \mathrm{O}$ Polarizability

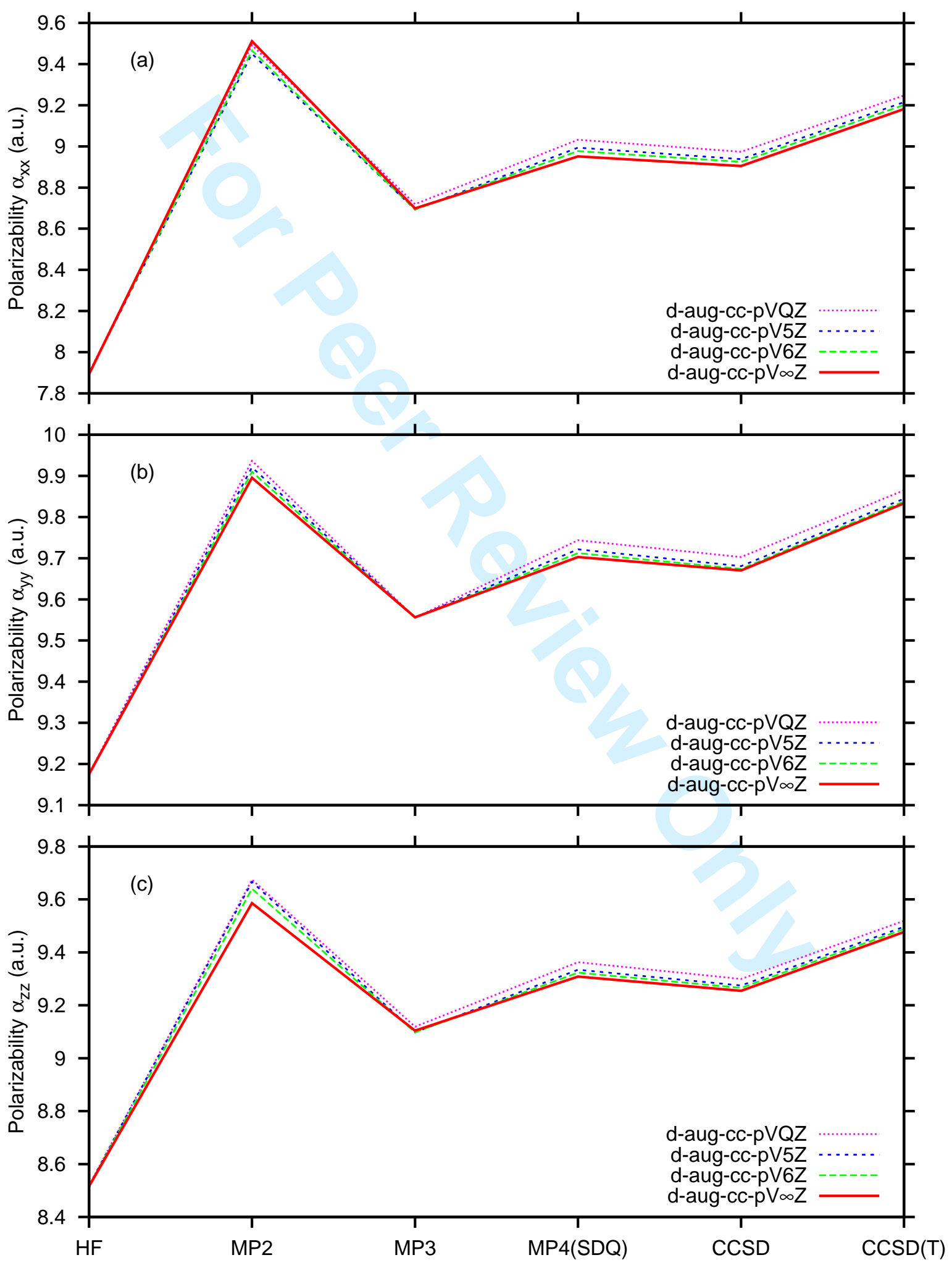


$\mathrm{C}_{2} \mathrm{H}_{2}$ Polarizability

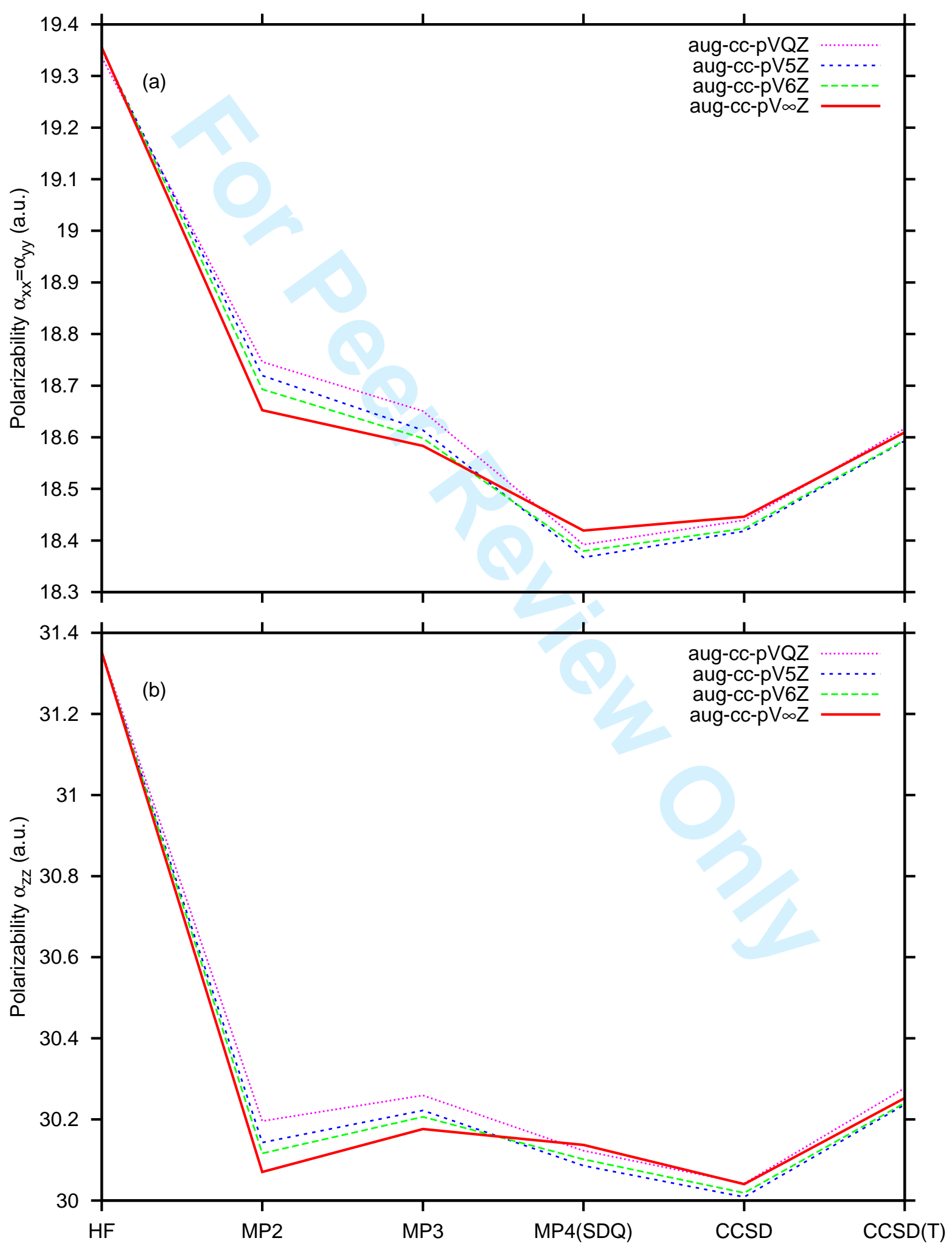




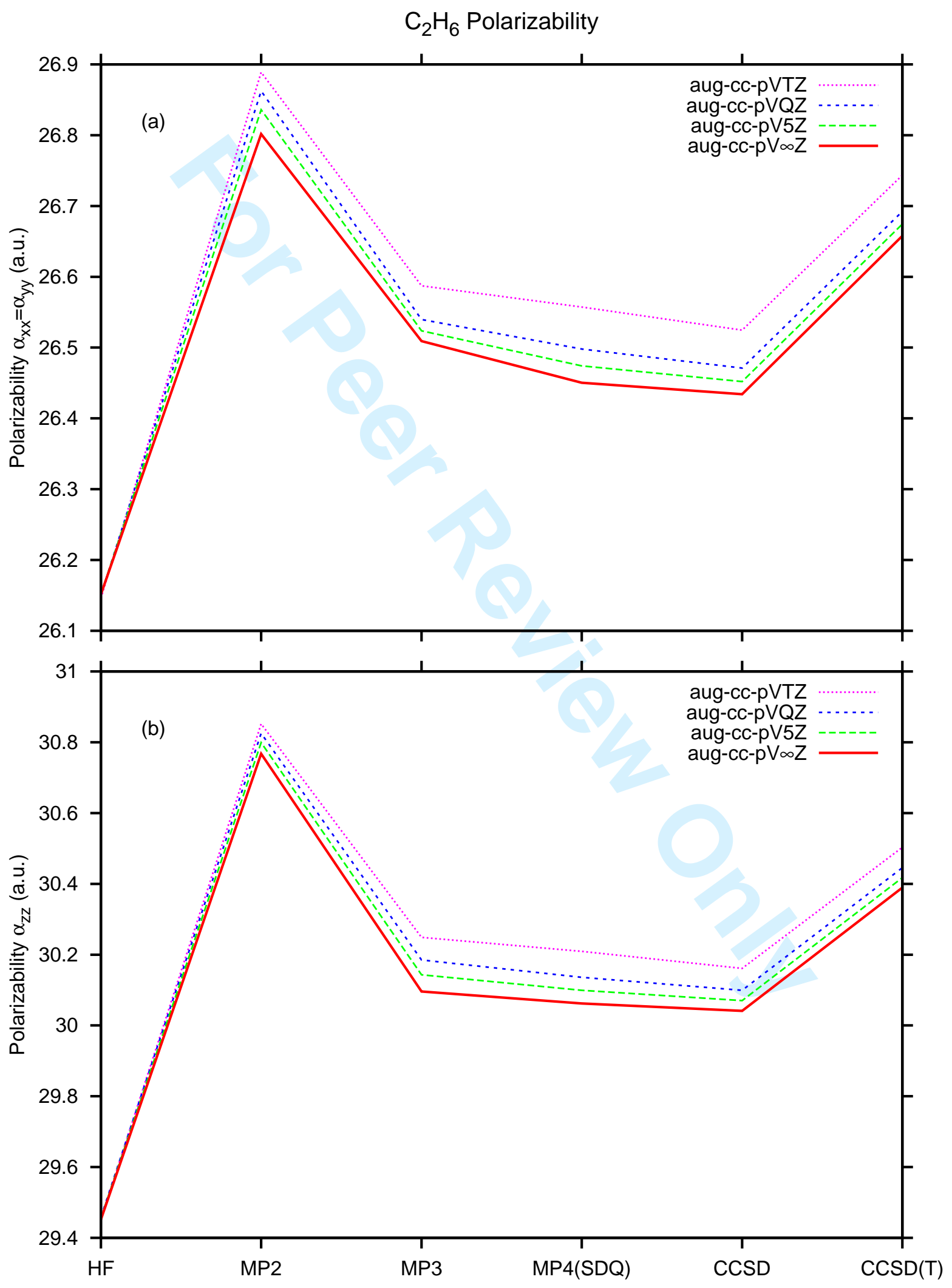

